\title{
Campaigned GPS on Present-Day Crustal Deformation in Northernmost Longitudinal Valley Preliminary Results, Hualien Taiwan
}

\author{
Chia-Yu Chen ${ }^{1,4}$, Jian-Cheng Lee ${ }^{2, *}$, Yue-Gau Chen ${ }^{1}$, and Rou-Fei Chen ${ }^{3}$ \\ ${ }^{1}$ Department of Geosciences, National Taiwan University, Taipei, Taiwan \\ ${ }^{2}$ Institute of Earth Sciences, Academia Sinica, Taipei, Taiwan \\ ${ }^{3}$ Department of Geology, Chinese Culture University, Taipei, Taiwan \\ ${ }^{4}$ Department of Earth Sciences, ETH, Zürich, Switzerland
}

Received 15 July 2013, accepted 25 December 2013

\begin{abstract}
The Longitudinal Valley in Eastern Taiwan sits at the collision suture between the Eurasian and Philippine Sea plates. Based on repeated GPS campaigned measurements from 25 stations six times in 2007 - 2009, we characterize the surface deformation in the northernmost Longitudinal Valley where the Coastal Range of the Philippine Sea plate turns northward diving under the Eurasian plate producing two major active faults: the Milun fault and the Longitudinal Valley fault. We reconstructed a GPS velocity field and conducted strain analyses and elastic block modeling. Our results suggest a rapid clockwise rotation of $33^{\circ} \mathrm{Myr}^{-1}$ and an eastward tectonic escape in the small Hualien City block (HUAL) area of $\sim 10 \times 10 \mathrm{~km}$, which is apparently detached from the regional rotating RYUK block defined by previous studies. We interpret it as being initiated locally by the northwest indentation of the Coastal Range, which pushed the HUAL block to move upward and eastward. According to our strain analyses, the HUAL block shows a significant internal elastic strain inside the Milun Tableland, the hanging wall of the Milun fault. No significant deformation was observed across the surface trace of the fault, indicating that the Milun fault is now probably locked in the near surface. The deformation in the footwall of the fault was accommodated by pure-shear strain with a major NNW-compression and a minor ENE-extension. The deformation in the hanging wall is characterized by simple-shear strain with ENE-extension in its northern part and little deformation in the southern part, separated by a little known NW-trending active fault zone (Dongmingyi fault), which needs further investigation.
\end{abstract}

Key words: Block rotation, Tectonic escape, GPS, Plate corner, Longitudinal Valley, Taiwan

Citation: Chen, C. Y., J. C. Lee, Y. G. Chen, and R. F. Chen, 2014: Campaigned GPS on Present-day crustal deformation in northernmost Longitudinal Valley preliminary results, Hualien Taiwan. Terr. Atmos. Ocean. Sci., 25, 337-357, doi: 10.3319/TAO.2013.12.25.01(TT)

\section{INTRODUCTION}

The Taiwan mountain belt is the product of a PlioPleistocene arc-continental collision in which the Luzon arc of the Philippine Sea plate obliquely collides with the Chinese continental margin of Eurasia (Fig. 1a) (Suppe 1984; Barrier and Angelier 1986; Ho 1986; Teng 1990). The 180-km-long Longitudinal Valley in Eastern Taiwan represents the plate suture along which active left-lateral oblique thrusting of the Longitudinal Valley Fault (LVF in Fig. 1a) accommodates the present surface horizontal shortening of $2-3 \mathrm{~cm} \mathrm{yr}^{-1}$, which is about one-third of the $8.2 \mathrm{~cm} \mathrm{yr}^{-1}$ tectonic contraction across the whole Taiwan mountain belt

\footnotetext{
* Corresponding author

E-mail:jclee@earth.sinica.edu.tw
}

(Biq 1965; Ho 1986; Yu et al. 1990; Lee and Angelier 1993; Angelier et al. 1997; Yu et al. 1997; Lee et al. 2003). On the northern and southern tips of the NNE-trending Taiwan mountain belt, the Ilan and Pingtung plains, show both lateral tectonic escape and/or horizontal strata bending with a rather complex combination of deformation features, such as block rotation, strike-slip faulting (i.e., shearing) and normal faulting (i.e., extension) (Angelier et al. 1990; Lu et al. 1995; Rau et al. 2008; Angelier et al. 2009; Ching et al. 2011). Recently, Rau et al. (2008) and Ching et al. (2011) analyzed GPS data and illustrated a significant plate-corner rotation occurring south of the Ilan plain area in northeastern Taiwan. Although the rates derived from their studies are slightly different, both of them interpreted it as a result 
of block rotation induced by Philippine Sea plate indentation into the Chinese continental margin, significantly enhanced by southward opening (pull-apart) of the Okinawa trough. The colliding point of the indenter was estimated near the coast between Suao and Hualien (Fig. 1b), which appears to be $20-30 \mathrm{~km}$ further north of the present on-land location of the Luzon arc and the Longitudinal Valley. On the other hand, the crustal deformation of the Hualien City area, which is situated geographically and geologically at the northernmost Longitudinal Valley, remains questionable in terms of the structural relationship with the Luzon arc collision on top of the Philippine Sea plate. A recently released island-wide network of continuous GPS data (http:// gps.earth.sinica.edu.tw) suggests that the northernmost
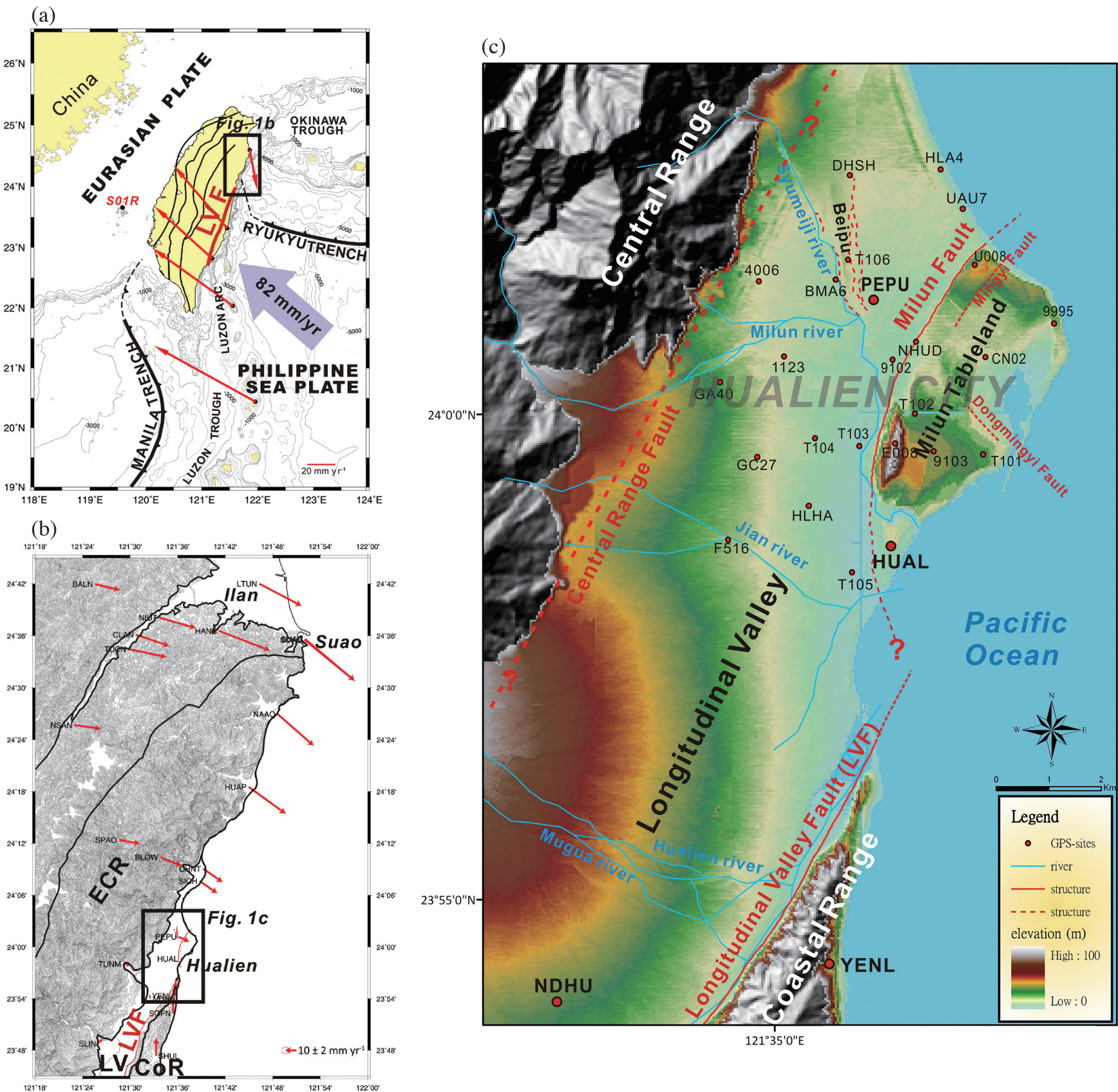

Fig. 1. (a) Tectonic setting of Taiwan. Red arrows illustrate the GPS velocity vectors against the station S01R located in Penghu. The Philippine Sea plate moves toward NW direction relative to the Eurasian plate at the rate of $82 \mathrm{~mm} \mathrm{yr}^{-1}$ (Yu et al. 1997). LVF: Longitudinal Valley Fault. (b) GPS velocity vectors (in the ITRF2000 frame) at the corner of the NW-directed Luzon arc and the Philippine Sea plate. The GPS vectors marked by red arrows, data from GPSLab of Academia Sinica (http://gps.earth.sinica.edu.tw). Both GPS vectors and geological units illustrate a significant clockwise rotation occurred in Ilan to Hualien area. ECR: Eastern flank of Central Range; LV: Longitudinal Valley; CoR: Coastal Range. (c) Shaded relief DEM map of the Hualien City area. Red solid circles represent the locations of our campaigned GPS sites in this study; the bigger circles are four continuous stations. Red lines (or dashed lines) illustrate geologically mapped active faults in this area. 
Longitudinal Valley belongs to the rotating block between Hualien and Ilan (Fig. 1b). As a result we attempted to solve this paradox about the rotating block at the northern plate corner of the indenting Luzon arc.

This paper focuses on characterizing the Present-day active surface deformation at the north end of the Longitudinal Valley. The study area, where Hualien City is located, is also at the transition zone of plate configuration flipping where the Philippine Sea plate turns from overriding the Eurasian plate in the south to subducting to it in the north (Suppe 1984; Burbank and Anderson 2001; Lallemand et al. 2001; Malavieille et al. 2002). According to previous seismological analyses, to the north of Hualien, the present shallow crustal deformation from Ilan to Hualien is accommodated by abundant faulting with a rather complex pattern, a mixture of normal faulting, thrust faulting and strike-slip faulting (Kao et al. 1998; Rau et al. 2008; Wu et al. 2009). In contrast, to the south of Hualian along the western side of the Coastal Range, both the geodetic and seismological data show predominantly thrust-style deformation concentrated along the major geological mapped fault, the LVF, with a minor left-lateral strike-slip component (Yu and Lee 1986; Lee and Angelier 1993; Lu et al. 1995; Yu et al. 1997; Kao and Jian 2001; Yu and Kuo 2001; Rau et al. 2008; Angelier et al. 2009). In summary, the styles of crustal deformation change substantially from shortening in southern Hualien (i.e., the Luzon arc of the Coastal Range) to extrusion and rotation in the Suao and Ilan area (i.e., the eastern edge of the Chinese continental margin). However, how the deformation style changes and where the exact transition occurs remains uncertain.

In this study we installed a dense GPS (Global Positioning System) network composed of about 25 campaigned stations with a station-spacing about $1-2 \mathrm{~km}$ incorporated with the existing 4 continuous GPS stations in the Hualien City area (Fig. 1c). We then carried out field measurements repeatedly 6 times in 2007 - 2009 in an attempt to better characterize the crustal deformation. We thus obtained a GPS horizontal velocity field and subsequently conducted strain analyses and elastic block modeling. Our result showed that the crustal deformation in the Hualien City area is undergoing a significant horizontal clockwise rotation and likely an eastward tectonic escape. We interpreted it as a result of northward squeeze from the Coastal Range. The colliding point is estimated to be near the northern tip of the Coastal Range. We also discussed the present state of the Milun fault, a major active fault in the study area that ruptured with surface breaks in the $1951 \mathrm{M}_{\mathrm{L}}=7.3$ earthquake, and its relationship with the LVF.

\section{GEOLOGICAL SETTING}

The NNE-striking 180-km-long Longitudinal Valley is an extraordinary geomorphological feature in Eastern
Taiwan. It separates two major geological units, the Central Range belonging to the Chinese continental margin in the west and the Coastal Range belonging to the Luzon arc in the east (Fig. 1). Hualien City, the most populated city in the valley with 110 thousands inhabitants, is located at the north end of the Longitudinal Valley (Fig. 1c).

The west side of the Longitudinal Valley, the eastern flank of the Central Range, where the mountain rises up rapidly to a few thousand meters high, is composed of preTertiary metamorphic complex (the Tananao Schist) which is the oldest geologic-tectonic unit in Taiwan. The Tananao metamorphic complex has been highly deformed and undergone multiple metamorphism episodes during two major geological events: the late Mesozoic orogenesis and the Plio-Pleistocene arc-continent collision (Jahn et al. 1986; Yui et al. 1990). The Central Range is bounded with the Longitudinal Valley, possibly by the Central Range fault, which was previously proposed to be a west-dipping high angle fault (Hsu 1962; Biq 1965; Ho 1982). However, the fault remains speculative because of lack of surface outcrop and subsurface geophysical evidence. The earthquake focal mechanism solutions beneath the eastern Central Range at $15-25 \mathrm{~km}$ depth indicate that thrust faulting (mostly the east-vergent back-thrusting) predominated deformation throughout this region, although its location does not correspond well to the down-dip projection of the Central Range fault. While normal faulting occurs, although more sparsely, most extensional earthquakes were found within the Tananao complex, which is believed to be related to either mountain collapse in the late mountain building stage (Crespi et al. 1996; Lin et al. 1998; Kuochen et al. 2004) or rapid exhumation of the Central Range (Lin 2000).

To the southeast of Hualien City the Coastal Range represents the northern end of the Luzon arc system (Fig. 1a). The Coastal Range is composed of the Miocene-Pliocene volcanic basement and the overlying Pliocene-Pleistocene turbidite, mélange and fringing-reef limestone (Teng and Wang 1981; Ho 1982; Chen and Wang 1986). The Coastal Range is attached to and thrust over the late Quaternary alluvial deposits of the Longitudinal Valley along the LVF. The earthquakes distribution and focal mechanisms indicate that the average fault plane strike of the central-southern part of the LVF is $\mathrm{N} 20^{\circ}-25^{\circ} \mathrm{E}$ with a listric-shaped dip of $25^{\circ}-70^{\circ}$ (Lee et al. 2003; Kuochen et al. 2004; Lee et al. 2006). The seismicity from Hualien to Taitung in Eastern Taiwan can be grouped into north and south portions, separated near the middle of the Coastal Range. In the north portion there have been thrust-type and also a few normal and strike-slip earthquakes (Hsu 2001; Yu and Kuo 2001; Kuochen et al. 2004). In contrast the southern portion of the LVF revealed a dominant thrust-type earthquake faulting mechanism with minor strike-slip faulting (Barrier and Angelier 1986; Chen and Rau 2002; Kuochen et al. 2004; Wu et al. 2006; Wu et al. 2008). According to the 1991 - 1999 GPS campaigned 
measurements, more than one-third of plate convergence of about $3 \mathrm{~cm} \mathrm{yr}^{-1}$ is attributed to horizontal shortening across the LVF at the middle and southern part of the valley (Yu et al. 1990; Lee and Angelier 1993; Yu and Kuo 2001). However, the northern segment of the LVF seems to be locked at the present time, indicated by a slow velocity increase gradient across the LVF and the Coastal Range ( $\mathrm{Yu}$ and Kuo 2001). In addition, the GPS vectors showed a clockwise rotation in the northernmost Coastal Range and there appears a possible left-lateral creep along the Milun fault based on trilateration repeated measurements in the Hualien area during the 80s (Yu et al. 1990).

Within the valley around Hualien City the surface is covered mainly by Holocene alluvial deposits, which were transported by rivers draining from the Central Range. Nevertheless, an abnormal geomorphic high consisting of late Quaternary uplifted marine terraces, the Milun Tableland of about $2 \mathrm{~km}$ wide, $8 \mathrm{~km}$ long, up to $100 \mathrm{~m}$ high, sits in isolation on the northeastern coast of the Hualien area (Fig. 1c). The 40m-DTM (Digital Terrain Model) shows that there are at least nine different terrace levels that can be identified in the Milun Tableland. Terraces in the northern part of this tableland are tilted slightly toward the southeast, but no tilting is observed in the southern part. These tilted terraces were interpreted to be strongly related to the long-term repeated movements on the hanging-wall side of the Milun fault with an estimated Holocene uplift rate of about $5 \mathrm{~mm} \mathrm{yr}^{-1}$ (Yamaguchi and Ota 2004).

The Milun fault is the most predominant deformation structure in northern Hualien and it closely follows the western edge of the Milun Tableland with a northeast strike and an onshore length of $\sim 8 \mathrm{~km}$, presumably with an offshore length of at least $20-30 \mathrm{~km}$. The fault historically ruptured during the October 22, $1951 \mathrm{M}_{\mathrm{L}}=7.3$ Hualien Earthquake, revealing coseismic surface breaks with an offset of about 1.2 and $2 \mathrm{~m}$ for its vertical and left-lateral strike-slip components, respectively (Hsu 1955). As for the interseismic slip, an elastic dislocation modeling based on 1985 - 1988 trilateration measurements suggested a best fit with a dip-angle of $51^{\circ}$ of the Milun fault toward the east and an oblique left-lateral reverse creep at a rate about 25 and $12 \mathrm{~mm} \mathrm{yr}^{-1}$ in horizontal and vertical components, respectively (Yu et al. 1990). As a result, the coseismic and interseismic deformation both consistently indicated that the Milun fault exhibited a mainly sinistral reverse slip. However, because of the lack of geological outcrop and little seismological constraint, the geometry of the Milun fault remains problematic.

In addition to the Milun fault, several possible subsidiary active structures have been documented by their abnormal geomorphic features (Fig. 1c), such as the Beipu structure, an abnormal relief on a flat fluvial plain (Chen et al. 2008); the Mingyi fault and the Dongmingyi fault, proposed by their linear scarps in the Milun Tableland (Yang 1986; Yu 1994; Lin and Hsiao 1998). There is unfortunately no outcrop of these possible active faults, so these structures are still questionable.

On a regional scale the overall structural architecture in the Hualien area also remains little known. For instance, the relationship between the Milun fault and the LVF on the northern extension of the Coastal Range is unclear, although some suspected that the Milun fault is a branch of the LVF (Hsu 1962). Furthermore, it is not clear how the metamorphic rocks of the Central Range interact with the Luzon arc system at depth.

\section{DENSE GPS NETWORK AND DATA PROCESSING}

In order to better characterize crustal deformation in the Hualien area, a dense network with about 25 campaign GPS stations was installed to deploy repeated measurements since 2007 (Fig. 1c). Several important factors, both scientific and technical, have been taken into account when selecting the location for the GPS sites, including: (a) complete station coverage in the northern Longitudinal Valley; (b) relatively good control for detecting the near-fault deformation associated with the Milun fault; (c) site ground stability and duration; (d) an unobstructed view of the sky above an elevation of 15 degrees and no reflecting surfaces or nearby heavy electrical devices. In addition to installing new benchmarks, we also adopted a few pre-existing benchmarks implanted by the government for city planning. As a result, our dense GPS network of 25 stations covered the northernmost Longitudinal Valley area of about $15-\mathrm{km}$ wide and $15-\mathrm{km}$ long with an average station spacing of $1-2 \mathrm{~km}$ (Fig. 1c). Our dense GPS station network is also coupled with 4 nearby continuous stations (PEPU, HUAL, NDHU, and YENL), that were previously installed and operated by academic institutions or government agencies (i.e., Academia Sinica and Central Weather Bureau).

Six static campaigned GPS surveys with intervals of 4 - 6 months were carried out from April 2007 to July 2009 (Table 1); each station was measured with TRIMBLE receiver 4000SSE and antenna TRM23903 or TRM22020 twice with an observation time of at least 8 hours at each session. Data were processed session by session using Bernese software v5.0 (Dach et al. 2007) to obtain the precise station coordinates under the WGS84 coordinate system. The final precise ephemerides provided by the International GPS Service for Geodynamics (IGS) were employed. In order to obtain the station velocity, we first calculated GPS velocities with respect to a reference point, S01R at Penghu in the Taiwan Strait (see location in Fig. 1a). This fixed reference is considered to be located in a relatively tectonically stable area on the Chinese continental shelf and is about $210 \mathrm{~km}$ away from our GPS network. The velocity and the uncertainty of each station were calculated by adopting the least square equation for an associated time series linear fit 
Table 1. Campaigned GPS stations with their survey periods in 2007 - 2009.

\begin{tabular}{|c|c|c|c|c|c|c|c|}
\hline $\begin{array}{l}\text { Ttation } \\
\end{array}$ & April 07 & August 07 & January 08 & July 08 & February 09 & July 09 & Measured times \\
\hline 1123 & $\mathrm{v}$ & $\mathrm{v}$ & $\mathrm{v}$ & $\mathrm{v}$ & $\mathrm{v}$ & $\mathrm{v}$ & 6 \\
\hline 4006 & & $\mathrm{v}$ & $\mathrm{v}$ & $\mathrm{v}$ & $\mathrm{v}$ & $\mathrm{v}$ & 5 \\
\hline 9102 & $\mathrm{v}$ & $\mathrm{v}$ & $\mathrm{v}$ & $\mathrm{v}$ & $\mathrm{v}$ & $\mathrm{v}$ & 6 \\
\hline 9103 & $\mathrm{v}$ & $\mathrm{v}$ & $\mathrm{v}$ & $\mathrm{v}$ & $\mathrm{v}$ & $\mathrm{v}$ & 6 \\
\hline 9995 & $\mathrm{v}$ & $\mathrm{v}$ & $\mathrm{v}$ & $\mathrm{v}$ & $\mathrm{v}$ & $\mathrm{v}$ & 6 \\
\hline BMA6 & $\mathrm{v}$ & $\mathrm{v}$ & $\mathrm{v}$ & $\mathrm{v}$ & $\mathrm{v}$ & $\mathrm{v}$ & 6 \\
\hline $\mathrm{CNO} 2$ & $\mathrm{v}$ & $\mathrm{v}$ & $\mathrm{v}$ & $\mathrm{v}$ & $\mathrm{v}$ & $\mathrm{v}$ & 6 \\
\hline DHSH & $\mathrm{v}$ & $\mathrm{v}$ & $\mathrm{v}$ & $\mathrm{v}$ & $\mathrm{v}$ & $\mathrm{v}$ & 6 \\
\hline E008 & $\mathrm{v}$ & $\mathrm{v}$ & $\mathrm{v}$ & $\mathrm{v}$ & $\mathrm{v}$ & $\mathrm{v}$ & 6 \\
\hline F516 & $\mathrm{v}$ & $\mathrm{v}$ & $\mathrm{v}$ & $\mathrm{v}$ & $\mathrm{v}$ & $\mathrm{v}$ & 6 \\
\hline GA40 & $\mathrm{v}$ & $\mathrm{v}$ & $\mathrm{v}$ & $\mathrm{v}$ & $\mathrm{v}$ & $\mathrm{v}$ & 6 \\
\hline GC27 & $\mathrm{v}$ & $\mathrm{v}$ & $\mathrm{v}$ & $\mathrm{v}$ & $\mathrm{v}$ & $\mathrm{v}$ & 6 \\
\hline HLA4 & $\mathrm{v}$ & $\mathrm{v}$ & $\mathrm{v}$ & $\mathrm{v}$ & $\mathrm{v}$ & $\mathrm{v}$ & 6 \\
\hline HLHA & & $\mathrm{v}$ & $\mathrm{v}$ & $\mathrm{v}$ & $\mathrm{v}$ & $\mathrm{v}$ & 5 \\
\hline NDHU & $\mathrm{v}$ & $\mathrm{v}$ & $\mathrm{v}$ & $\mathrm{v}$ & $\mathrm{v}$ & $\mathrm{v}$ & 6 \\
\hline NHUC & $\mathrm{v}$ & $\mathrm{v}$ & $\mathrm{v}$ & $\mathrm{v}$ & $\mathrm{v}$ & $\mathrm{v}$ & 6 \\
\hline NHUD & $\mathrm{v}$ & $\mathrm{v}$ & $\mathrm{v}$ & $\mathrm{v}$ & $\mathrm{v}$ & $\mathrm{v}$ & 6 \\
\hline NHUE & $\mathrm{v}$ & $\mathrm{v}$ & $\mathrm{v}$ & $\mathrm{v}$ & $\mathrm{v}$ & $\mathrm{v}$ & 6 \\
\hline T101 & $\mathrm{v}$ & $\mathrm{v}$ & $\mathrm{v}$ & $\mathrm{v}$ & $\mathrm{v}$ & $\mathrm{v}$ & 6 \\
\hline T102 & $\mathrm{v}$ & $\mathrm{v}$ & $\mathrm{v}$ & $\mathrm{v}$ & $\mathrm{v}$ & $\mathrm{v}$ & 6 \\
\hline T103 & $\mathrm{v}$ & $\mathrm{v}$ & $\mathrm{v}$ & $\mathrm{v}$ & $\mathrm{v}$ & $\mathrm{v}$ & 6 \\
\hline T104 & $\mathrm{v}$ & $\mathrm{v}$ & $\mathrm{v}$ & & & & 3 \\
\hline T105 & $\mathrm{v}$ & $\mathrm{v}$ & $\mathrm{v}$ & $\mathrm{v}$ & $\mathrm{v}$ & $\mathrm{v}$ & 6 \\
\hline T106 & & $\mathrm{v}$ & $\mathrm{v}$ & $\mathrm{v}$ & $\mathrm{v}$ & $\mathrm{v}$ & 5 \\
\hline U008 & $\mathrm{v}$ & $\mathrm{v}$ & $\mathrm{v}$ & $\mathrm{v}$ & $\mathrm{v}$ & $\mathrm{v}$ & 6 \\
\hline UAU7 & $\mathrm{v}$ & $\mathrm{v}$ & $\mathrm{v}$ & $\mathrm{v}$ & $\mathrm{v}$ & $\mathrm{v}$ & 6 \\
\hline
\end{tabular}

for each station (Table 2, Fig. 2). The velocities were transferred into ITRF2000 values by adding the velocity value of station S01R under frame ITRF2000. This value was obtained from the GPSLab of Academia Sinica (http://gps. earth.sinica.edu.tw) using a least-squares fitting of the time series on the same duration as our measurements (Table 2, Fig. 3). Previous studies revealed that the relative positions of coordinates under the ITRF framework can be considered linear within a small area, for instance the area of Taiwan island (Kuo 2001).

\section{GPS RESULTS AND STRAIN ANALYSES}

\subsection{GPS Velocity Field in Hualien}

The time series plot (Fig. 2) shows that most of the stations' horizontal velocities fit rather well with a linear trend, both in north and east components. As a result, we consider this linear regression to represent the interseismic secular rate. Although there occurred three earthquake sequences of magnitude $5\left(\mathrm{M}_{\mathrm{L}} 5.1\right.$ on August $2^{\text {nd }} 2008, \mathrm{M}_{\mathrm{L}} 5.1$ on January $4^{\text {th }} 2009$ and $M_{L} 5.3$ on June $28^{\text {th }} 2009$ ) in the nearby area during this period of 2007 - 2009, they seemingly did not cause significant disturbance on the surface deformation in the Hualien area, at least not showing in our plots of time series.

We thus reconstructed the GPS horizontal velocity field with $95 \%$ confidence under the ITRF2000 frame in the Hualien area (Fig. 3). We can observe that the crustal motion is characterized by a clockwise rotation and a seemingly 
tectonic escape in the northernmost Longitudinal Valley coupled with a NNW-direction indentation in the Coastal Range. Continuous GPS (cGPS) station YENL, which sits on the northern tip of the Coastal Range, moves north at a rate of $12.9 \mathrm{~mm} \mathrm{yr}^{-1}$. The cGPS station NDHU on the valley side moves slightly toward the northwest at a slim rate of
$4.1 \mathrm{~mm} \mathrm{yr}^{-1}$, while most of the stations on the Hualien Plain move east to southeast with the velocities increasing gradually northward from $1.6 \mathrm{~mm} \mathrm{yr}^{-1}$ (HUAL) to $19.7 \mathrm{~mm} \mathrm{yr}^{-1}$ (9995), showing a clockwise rotation pattern on the northern half of the Hualien area.

In an attempt to better characterize the possible internal

Table 2. Horizontal velocity results from the GPS stations in the Hualien area. Station S01R is the fixed reference located at the Penghu Island in the Taiwan Strait. Lon: Longitude. Lat: latitude. $\mathrm{V}_{\mathrm{E}-\mathrm{S} 01 \mathrm{R}}$ : east component of GPS velocities related to station S01R. $\mathrm{V}_{\mathrm{N}-\mathrm{S} 01 \mathrm{R}}$ : north component of GPS velocities related to station S01R. $V_{\text {E-itrf: }}$ east component of GPS velocities on the ITRF2000 frame. $\mathrm{V}_{\mathrm{N} \text {-itrf: }}$ north component of GPS velocities on the ITRF2000 frame. $\mathrm{E}_{\mathrm{E}}$ : errors in east component of GPS velocities. $\mathrm{E}_{\mathrm{N}}$ : errors in north component of GPS velocities.

\begin{tabular}{|c|c|c|c|c|c|c|c|c|}
\hline Station & Lon $\left({ }^{\circ}\right)$ & Lat $\left(^{\circ}\right)$ & $\mathbf{V}_{\mathrm{E} \_ \text {S01R }}\left(\mathrm{mm} \mathrm{yr}^{-1}\right)$ & $\mathrm{V}_{\mathrm{N} \_ \text {S01R }}\left(\mathrm{mm} \mathrm{yr}^{-1}\right)$ & $\mathbf{V}_{\mathrm{E}_{-} \text {itrf }}\left(\mathbf{m m} \mathbf{y r}^{-1}\right)$ & $\mathbf{V}_{\mathrm{N}_{\mathrm{itrf}}}\left(\mathbf{m m} \mathbf{y r}^{-1}\right)$ & $E_{E}\left(m m y^{-1}\right)$ & $\mathbf{E}_{\mathrm{N}}\left(\mathbf{m m} \mathbf{y r}^{-1}\right)$ \\
\hline S01R & 119.58426 & 23.65698 & 0.000 & 0.000 & 26.400 & -16.000 & 0.000 & 0.000 \\
\hline 1123 & 121.58557 & 24.00982 & -19.656 & 14.382 & 6.744 & -1.618 & 1.430 & 1.095 \\
\hline 4006 & 121.58092 & 24.02276 & -17.164 & 11.631 & 9.236 & -4.369 & 1.216 & 3.066 \\
\hline 9102 & 121.60584 & 24.00917 & -20.049 & 11.680 & 6.351 & -4.320 & 1.431 & 0.988 \\
\hline 9103 & 121.61344 & 23.99340 & -22.774 & 17.101 & 3.626 & 1.101 & 1.121 & 0.909 \\
\hline 9995 & 121.63602 & 24.01527 & -7.655 & 9.812 & 18.745 & -6.188 & 1.841 & 1.001 \\
\hline BMA6 & 121.59521 & 24.02298 & -20.263 & 11.575 & 6.137 & -4.425 & 1.979 & 1.321 \\
\hline $\mathrm{CN} 02$ & 121.62320 & 24.00958 & -15.052 & 13.805 & 11.348 & -2.195 & 1.852 & 1.025 \\
\hline DHSH & 121.59797 & 24.04089 & -16.451 & 7.784 & 9.949 & -8.216 & 0.973 & 2.492 \\
\hline E008 & 121.60621 & 23.99476 & -19.886 & 10.480 & 6.514 & -5.520 & 1.938 & 3.893 \\
\hline F516 & 121.57498 & 23.97837 & -24.271 & 13.225 & 2.129 & -2.775 & 2.487 & 1.345 \\
\hline GA40 & 121.57356 & 24.00544 & -21.640 & 11.557 & 4.760 & -4.443 & 2.468 & 0.860 \\
\hline GC27 & 121.58046 & 23.99253 & -24.049 & 12.093 & 2.351 & -3.907 & 2.325 & 0.967 \\
\hline HLA4 & 121.61495 & 24.04180 & -16.376 & 9.166 & 10.024 & -6.834 & 1.856 & 0.628 \\
\hline HLHA & 121.59005 & 23.98411 & -29.158 & 16.069 & -2.758 & 0.069 & 2.038 & 2.607 \\
\hline HUAL & 121.60536 & 23.97719 & -24.945 & 16.750 & 1.455 & 0.750 & 1.319 & 0.236 \\
\hline NDHU & 121.54267 & 23.89905 & -27.924 & 19.814 & -1.524 & 3.814 & 1.364 & 0.498 \\
\hline NHUC & 121.61052 & 24.01196 & -18.816 & 13.543 & 7.584 & -2.457 & 1.409 & 1.981 \\
\hline NHUD & 121.61021 & 24.01222 & -20.048 & 10.444 & 6.352 & -5.556 & 0.465 & 1.007 \\
\hline NHUE & 121.61018 & 24.01259 & -21.485 & 11.250 & 4.915 & -4.750 & 1.329 & 0.928 \\
\hline PEPU & 121.60218 & 24.01969 & -18.497 & 10.628 & 7.903 & -5.372 & 1.169 & 0.767 \\
\hline T101 & 121.62268 & 23.99281 & -24.823 & 16.838 & 1.577 & 0.838 & 1.361 & 1.266 \\
\hline T102 & 121.60995 & 23.99985 & -24.622 & 16.119 & 1.778 & 0.119 & 2.961 & 2.791 \\
\hline $\mathrm{T} 103$ & 121.59952 & 23.99438 & -29.130 & 15.016 & -2.730 & -0.984 & 3.214 & 2.750 \\
\hline T104 & 121.59124 & 23.99574 & -28.699 & 19.787 & -2.299 & 3.787 & 9.288 & 2.880 \\
\hline T105 & 121.59807 & 23.97265 & -26.231 & 14.292 & 0.169 & -1.708 & 2.033 & 1.525 \\
\hline T106 & 121.59756 & 24.02638 & -11.925 & 9.126 & 14.475 & -6.874 & 1.913 & 1.698 \\
\hline TUNM & 121.48543 & 23.96701 & -20.835 & 15.585 & 5.565 & -0.415 & 2.391 & 0.818 \\
\hline U008 & 121.62124 & 24.02540 & -18.137 & 12.483 & 8.263 & -3.517 & 2.830 & 1.656 \\
\hline UAU7 & 121.61903 & 24.03504 & -15.088 & 8.276 & 11.312 & -7.724 & 2.928 & 1.172 \\
\hline YENL & 121.59370 & 23.90531 & -27.473 & 28.956 & -1.073 & 12.956 & 1.090 & 0.811 \\
\hline
\end{tabular}




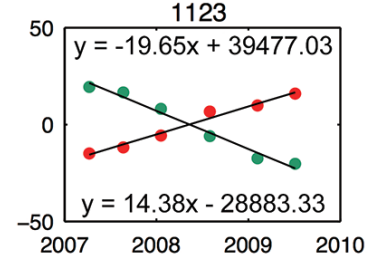

9995

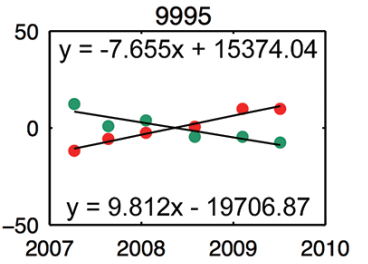

E008

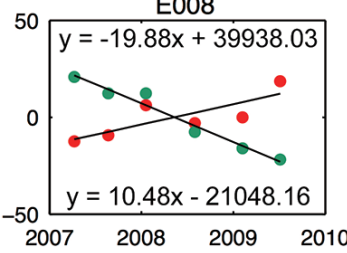

HLA4

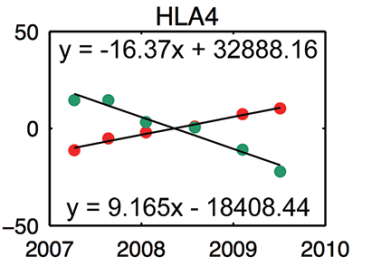

NHUC

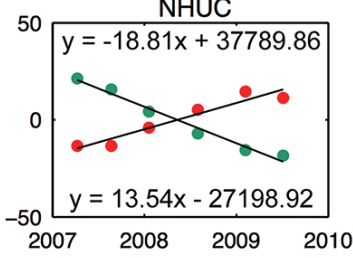

T101

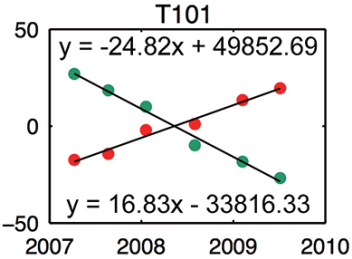

T105

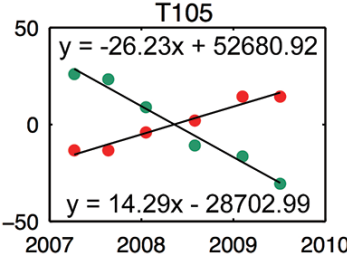

UAU7

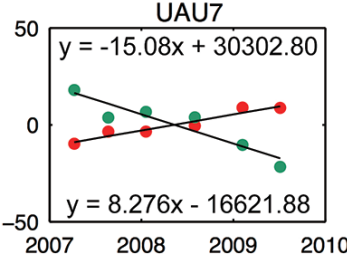

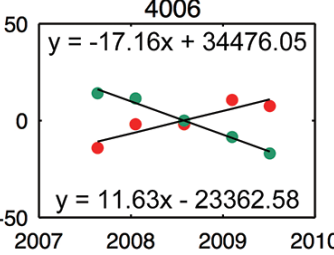

BMA6

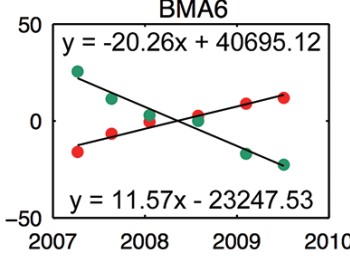

F516

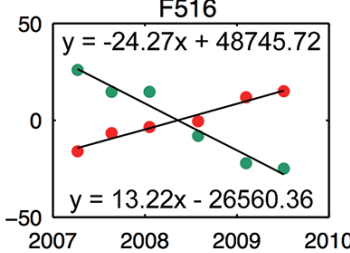

HLHA

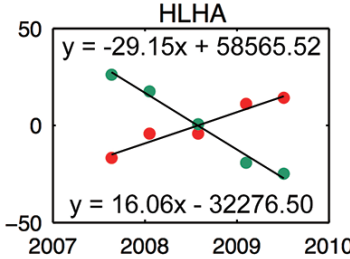

$2007 \quad 2008 \quad 2009$

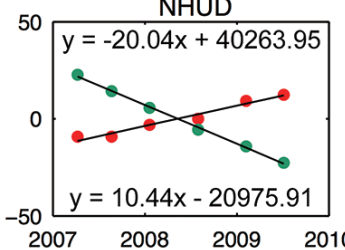

$\mathrm{T} 102$

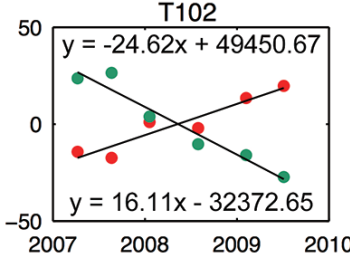

T106

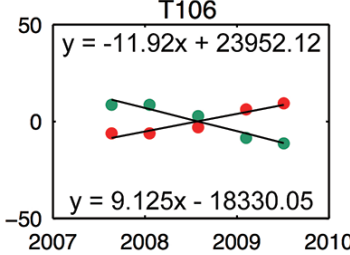

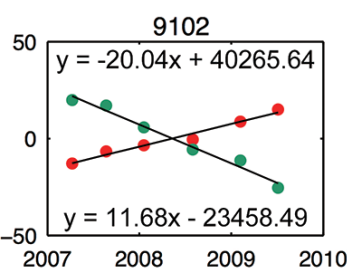

CN02

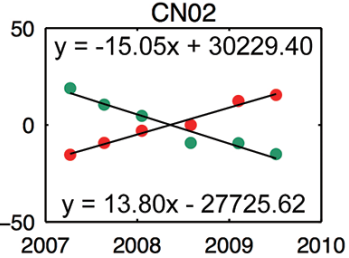

GA40

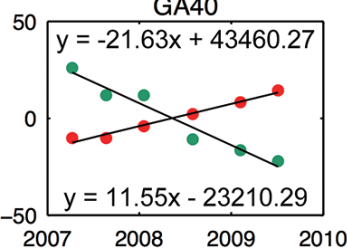

HUAL

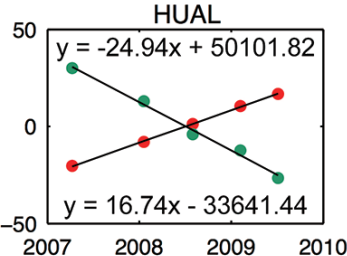

NHUE

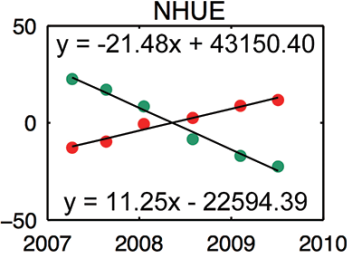

T103

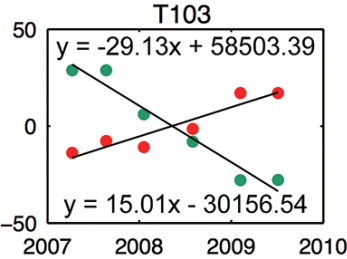

TUNM

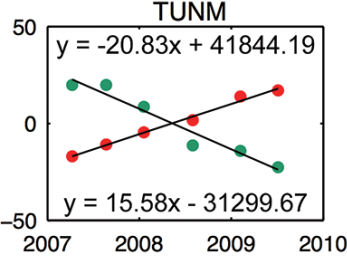

YENL

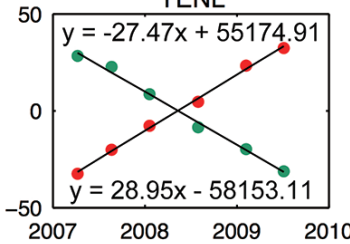

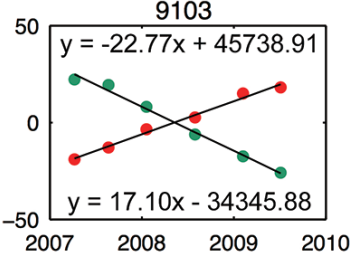

$\mathrm{DHSH}$

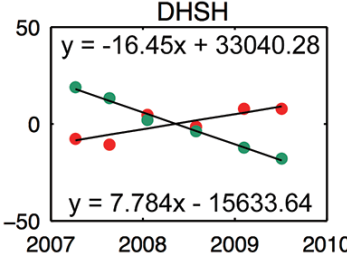

GC27

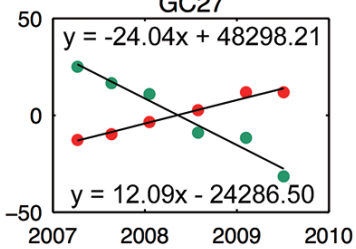

$\mathrm{NDHU}$

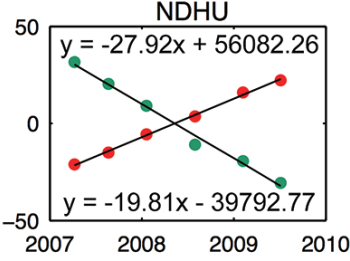

PEPU

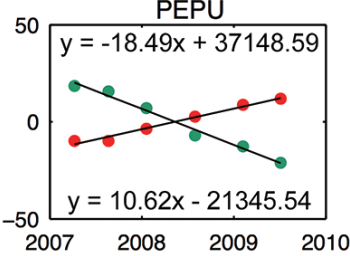

T104

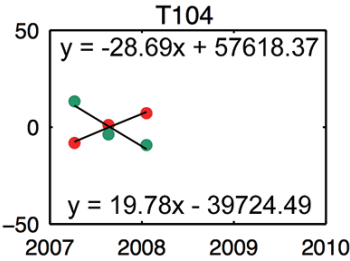

U008

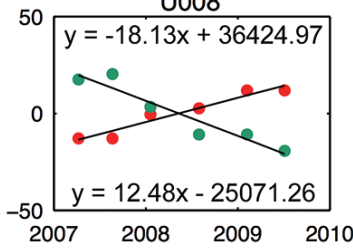

Fig. 2. Time series of GPS measurements from each campaigned and continuous GPS station. The distance changes for both the components of latitude $(\mathrm{N})$ and longitude (E) directions in millimeter are with respect to the S01R station in Penghu. The data shows that most of the stations' velocities fit rather well with a linear trend, both in the east (marked by green circles) and north (marked by red circles) components. The upper and lower formulas in each subplot represent the best fitting lines for the east and north components, respectively. 


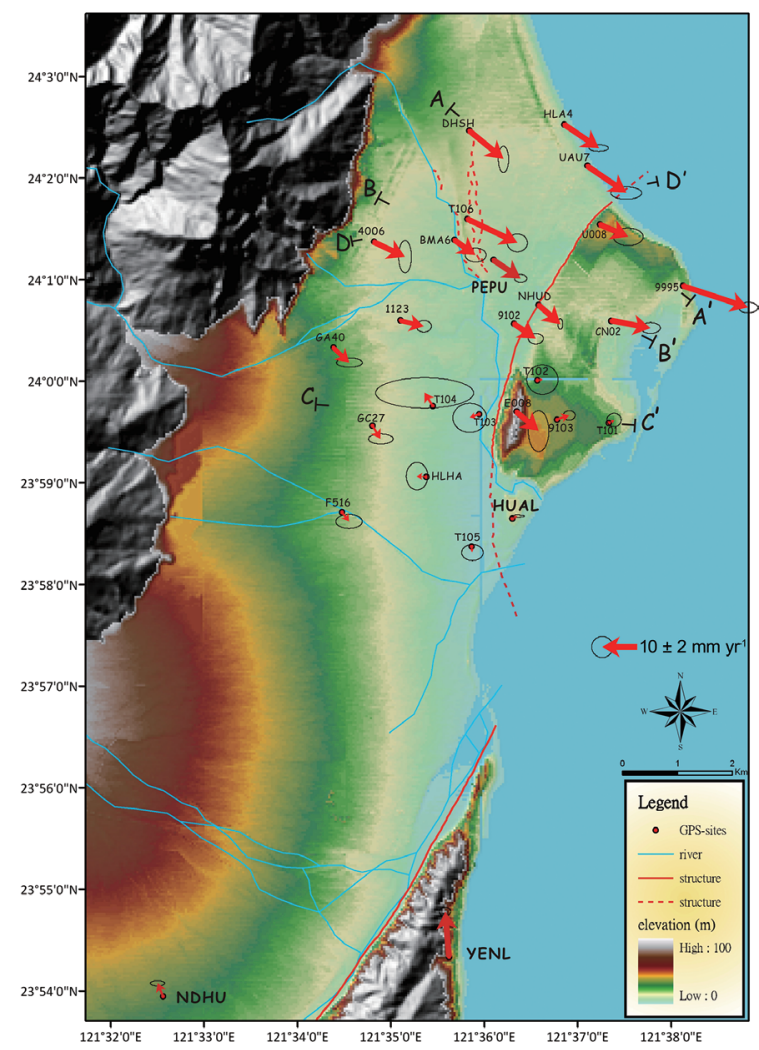

Fig. 3. GPS horizontal velocity field vectors (the ITRF2000 reference frame) in the Hualien area. The $95 \%$ confidence ellipses (1 $\sigma$ standard error) are shown on the tip of the arrows for velocity vectors. Most of the stations in the northernmost Longitudinal Valley move toward the east to southeast with the velocities increasing gradually northward, showing a clockwise rotation. The station YENL on the northern tip of the Coastal Range moves significantly toward north, by contrast the station on the Longitudinal Valley side (NDHU) moves at only very slight rate (toward northwest). The deformation in the area illustrates a seemingly lateral escape coupled with a NNW-direction indentation of the Coastal Range.

deformation within the rotating and escaping Hualien City area, we carried out strain analyses based on the GPS velocity field results. The observed duration of station T104 was too short (less than one year) and it revealed a relatively large standard deviation of station velocity, thus it was excluded from further analyses. We also conducted detailed analyses on the GPS displacements across the Milun fault to provide insights into the fault slip behavior and kinematics.

\subsection{Strain Analysis}

The strain rate distribution provides great help to better understand the type of deformation and strain accumulation on active faults and thus the earthquake potential. For the strain and rotation inversion the contribution of each station is usually weighted with a function that decays as the distance increases from the point to be estimated (Shen et al. 1996; Ward 1998). In this study, the Ward algorithm was adopted for estimating and analyzing the strain rates in the Hualien area. We first built a convex hull for strain calculation which included all observed stations with $0.01 \times 0.01$ degree spacing grids, and then calculated the dilatation rate, shear strain rate and rotation rate at each grid node constrained by the weighted velocities of the observed GPS stations. The weighting is given as,

$W_{i}=\exp \left(\frac{-d i s t_{i}^{2}}{2 D^{2}}\right)$

where dist $_{i}$ is the distance between the $i$ th GPS station and the estimating node point, and $D$ is the distance of the fourth closest station to the estimating point. In practice, at least 4 stations would be used for inversion on each grid node point.

We thus obtained maps of three types of strain rates in the study area (Fig. 4): dilation strain, shear strain and rotation strain. The positive and negative values in the dilatation rate indicate extension and shortening, respectively. The shear strain rate illustrates potential strike-slip faulting with the sense of motion along the possible locations of the shear planes. The rotation rate illustrates clockwise and counterclockwise rotation with positive and negative values, respectively.

The calculated dilatation rate (Fig. 4a) shows both extension and shortening occurred in the Hualien area with values between -1.35 to $1.20 \mu$ strain $\mathrm{yr}^{-1}$. The dilatational deformation was characterized by NNW - SSE shortening in the western plain area, west of the Milun Tableland (i.e., the Beipu area) and a more complex strain distribution in the Milun Tableland: dominant E-W to ENE-trending extension in the northern tableland and minor NNW-trending shortening in the south (Fig. 4a). We also noticed a small abnormal area that showed a slight ENE-trending extension in the southern plain close to the tableland. This NNWtrending shortening and ENE-trending extension coupling (which is perpendicular to NNW shortening) confirms that the Hualien City area crustal deformation is mainly a result of NNW-trending collision or indentation of the northern Coastal Range. It is worth noting that the dilatation rate was relatively small along the Milun fault surface trace, although some variation can be observed from north to south, indicating that there was no significant near-fault surface deformation (shortening or extension) across the Milun fault in 2007 - 2009.

As for the shear strain rate, we obtained a map of the shear strain rate distribution (Fig. 4b) with the values between $0.63-2.52 \mu$ strain $\mathrm{yr}^{-1}$, which should be considered significant at the kilometer spacing scale. In Fig. $4 \mathrm{~b}$ we elected to demonstrate the sinistral shear strain principal axes on the map (the dextral strain axis is thus perpendicular to the sinistral strain axis), because the Milun fault showed a significant left-lateral strike slip component during the 1951 
earthquake and 1985 - 1988 interseismic creep. We can observe that the large shear rate was not concentrated along the Milun fault surface trace. Instead, it was widespread inside the whole Milun Tableland (Fig. 4b). This phenom- enon could be caused either by Milun fault creeping in the deep part (e.g., visco-elastic ductile creep) or the existence of other undefined structures. Based on the shear strain rate result the substantial shear deformation was characterized
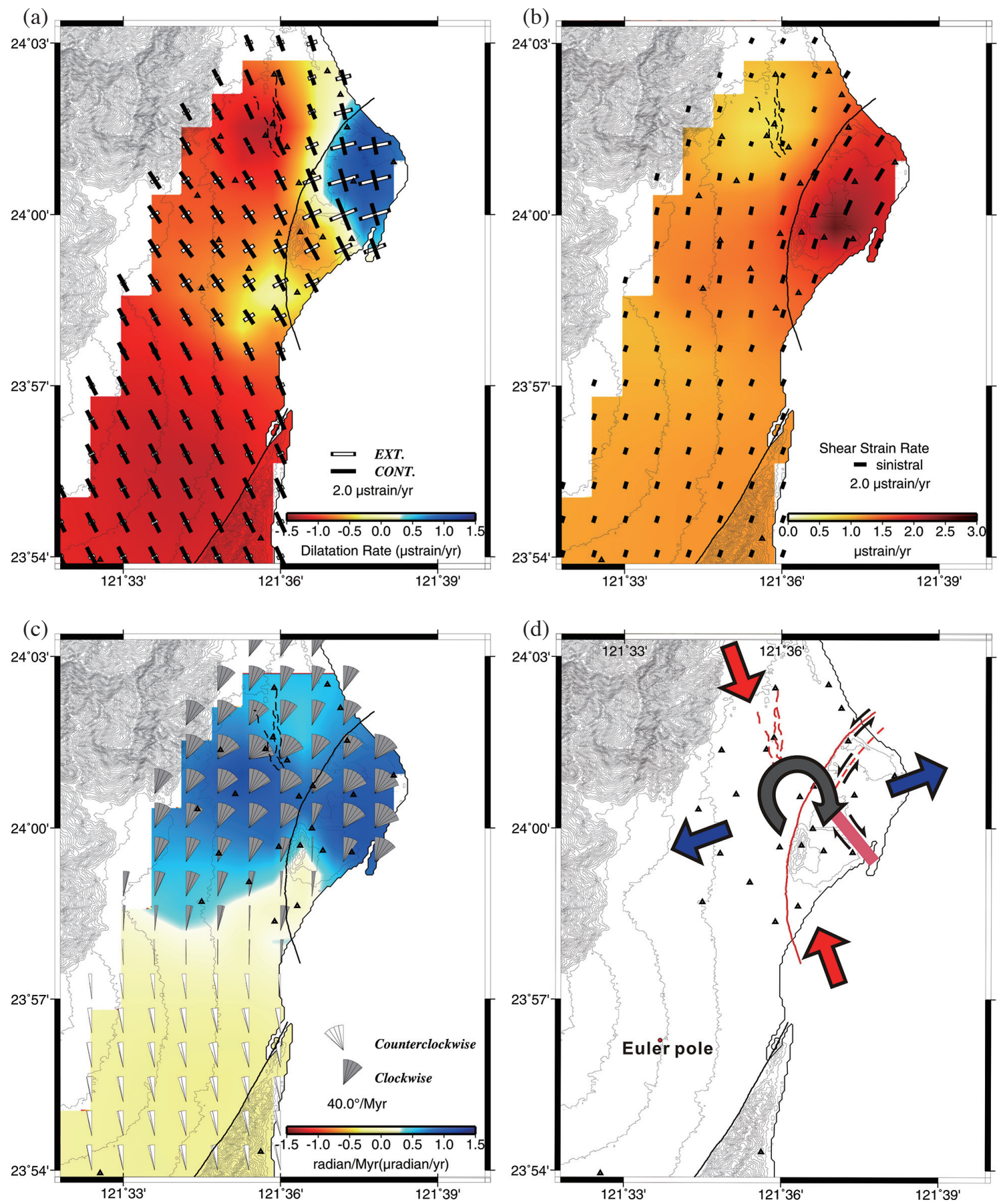

Fig. 4. Strain rate maps, including (a) dilatation strain, (b) shear strain and (c) rotation strain, derived from the GPS velocity field in the Hualien City area. Black triangles illustrate the GPS station locations. Three different strain rates at each grid node are shown by its associated symbol and value. For dilatation rate, the black bars and white bars illustrate shortening and extension principal strain axes relatively. Combination of ENE-trending extension and NNW-trending shortening suggests that the crustal deformation in the Hualien City area is mainly due to a NNW-trending collision or indentation result from the Coastal Range. For shear strain rate, the black bars illustrate the sinistral shear strain principal axes. Large shear rate is located in the Milun tableland and is accommodated by either NE-trending left-lateral shearing or NW-trending right-lateral shearing. For rotation rate, gray and white fans illustrate clockwise and counter-clockwise rotation, respectively. A large part of the Hualien area was dominated by a clockwise rotation, which diminished toward the south. (d) Tectonic kinematics interpretation from strain analysis in the Hualien area. 
by either NE-trending left-lateral shearing or NW-trending right-lateral shearing, particularly in the Milun tableland. It is thus possible that the left-lateral shearing is accommodated by a few (or a series of) parallel NE-trending strike-slip faults (i.e., multiple fault dislocations), which would be sub-parallel to the Milun fault. In fact, one NE-trending geomorphic scarp of a few kilometers long can be identified and mapped in the 40-m DTM (the Minyi fault in Figs. 1c and 4d). Another possibility which cannot be excluded is the existence of NW-trending right-lateral strike-slip fault. The middle of the Milun tableland shows a NW-trending concentration shear strain zone (Fig. 4b), which also corresponds to a NW-trending dilatation strain boundary (Fig. 4a) between the extension to the northeast and compression to the southwest. We noticed that the ancient Milun River had been flowing along the NW-trending zone in the middle of the Milun Tableland, also implying the possible active geological structure for this NW-trending zone.

The calculated rotation rate shows values between -0.29 to $1.20 \mu$ radian $\mathrm{yr}^{-1}$ (Fig. 4c), which are equivalent to $-16.6^{\circ}-69.9^{\circ}$ per Myr. In Fig. $4 c$, we observed that a large part of the Hualien area was dominated by a clockwise rotation, yielding an average rate of about $33^{\circ} \mathrm{Myr}^{-1}$ in the whole block. It is intriguing to find that the clockwise rotation diminished abruptly in the southern part of the Milun Tableland. We will discuss this later with our field geological observation and kinematic model concept.

\section{BLOCK ROTATION MODELING}

In order to test the surface deformation with the rotating block model we first estimated the would-to-be location of the rotation Euler pole in the Hualien area according to our GPS velocity field results. We adopted a numerical block rotation modeling code "defnode" by MaCaffrey (McCaffrey 2002). For reasons that the subsurface geometry of the Milun fault is still little known and that there is no significant velocity discontinuity across the fault, we would consider, at this first stage, not to put the Milun fault into the boundary condition of our numerical model. As a consequence, a single block, HUAL with no fault was defined while conducting this modeling (Fig. 5). The western margin of the HUAL block is defined following the eastern margin of the Central Range, which corresponds to a geologically suspected fault, the Central Range Fault (Biq 1965; Lu and Hsu 1992; Shyu et al. 2005). A recent study on local seismicity (Chen et al. 2012) suggested a seismically active structure along the edge of the Central Range in the Hualian City area. The southern margin of the HUAL block is to the north of the Coastal Range and the other two boundaries were set approximately to cover all of the Hualien area in the northernmost Longitudinal Valley. All of the four boundaries were not defined as faults for the sake of simplification. Thus, they were handled as freely creeping

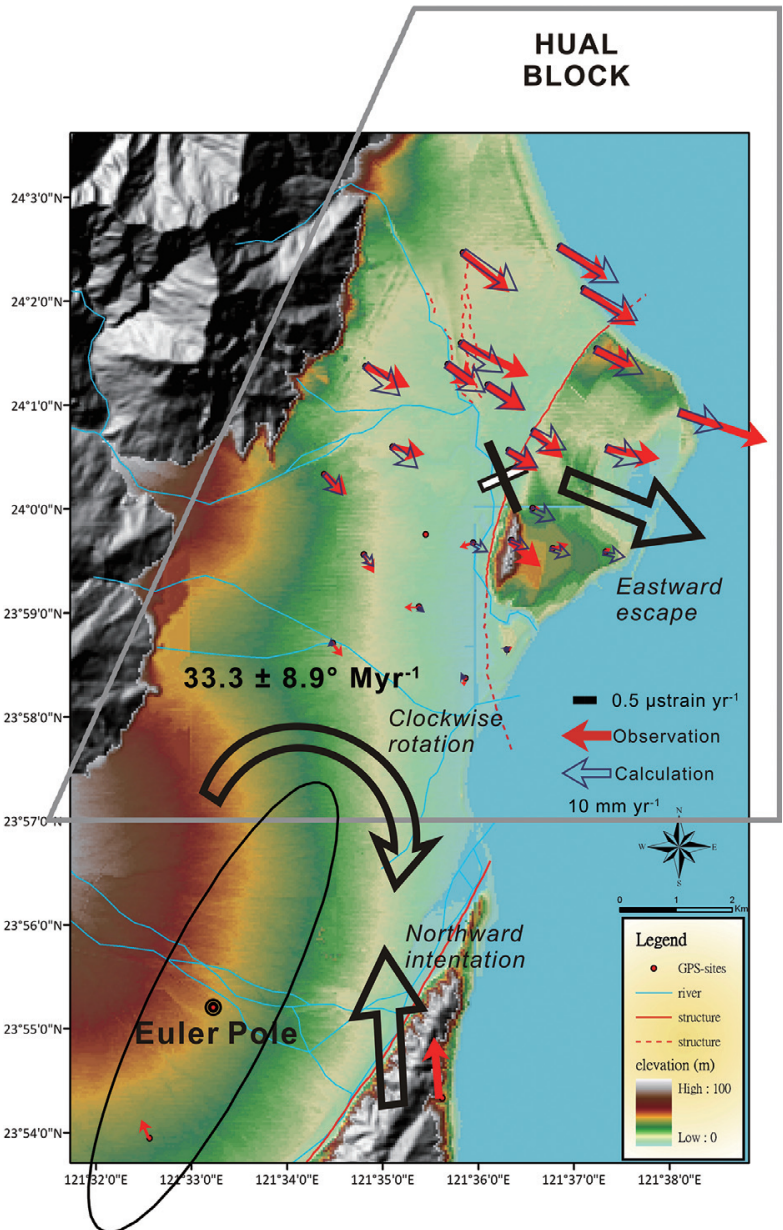

Fig. 5. Results of the elastic block rotation modeling in the Hualien City area, showing a good fit with a clockwise rotation at an angular velocity of about $33^{\circ} \mathrm{Myr}^{-1}$ coupled with a NE shortening strain and a NW extension strain (indicated by solid heavy bar and white bar). The corresponding Euler pole is found to be located southwest of the Hualien City block. See Tables 3 and 4 and main text for details.

boundary during the modeling and therefore do not have any effect on the model. We tested two different block rotation models: (1) rigid block (without internal strain) and (2) elastic block (with internal strain). Note that the reference (i.e., fixed point) for rotating blocks would be Earth's center since the ITFR frame is adopted for the station velocity determination. The reduced $\chi^{2}$ is used to find the best-fitting model, and it is defined as,

$\chi_{r}^{2}=\frac{\sum_{i=1}^{n}\left(\frac{r_{i}}{\sigma_{i}}\right)^{2}}{n-m}$

where $n$ is the number of observed data, $r_{i}$ is the observed minus calculated velocity of each observed point, $\sigma$ is the uncertainty of the observed data, and $m$ is the number of free parameters (McCaffrey 2002). The results of models we built are listed in Tables 3 and 4 . 
Our results indicate that the elastic block model with internal strain fits the observation better than the rigid block model. Our results show that the horizontal velocity field in the Hualien area generally corresponds to a clockwise rotation at a rate of $33.3 \pm 8.9^{\circ} \mathrm{Myr}^{-1}$ (Fig. 5). The Euler pole of the rotating HUAL block is calculated as located southwest of Hualien City and west of the northern tip of the Coastal Range (Fig. 5), although a relatively large location uncertainty exists in the NNE-trending direction. We tend to consider this Euler pole to represent the colliding point of the indenting Coastal Range. We also found that some of the calculated velocities in the southern part of Hualien City do not fit quite well with the observed velocities. We interpreted that it might be due to a local effect in the southern Milun Tableland, implying that the whole study area deformation is accommodated by a few sets of local faulting discussed above, in addition to the regional block rotation. The southern Milun Tableland behaves a little differently, although the deformation is at a lesser degree compared to the regional clockwise rotation.

In addition to the Hualien City (HUAL) block rotation modeling we also calculated the regional block rotation rates and Euler pole positions to decipher the crustal deformation behavior at a large spatial scale from the Ilan to Hualien areas. The GPS velocities of stations to the north of Hualien were acquired from the GPSLab of Academia Sinica, using the same approach as mentioned in the previous GPS data processing section. From the first glance of GPS velocity data in the area from Ilan to Hualien (Fig. 6), it appears that the Hualien City area exhibits a small individual rotating block within the regional rotating block from Ilan to Hualien. As a result, we conducted two models with different block configurations: first we considered the whole area from Ilan to Hualien as a single block "ILHU" (Fig. 7a) with the northern and western margins defined by regional major faults and other two boundaries following the GPS data geographic distribution limits. For the second model we considered the Hualien City area as a small block (HUAL, the block we used to model above), which is separated from the "RYUK" block (Fig. 7b). As discussed above, we also applied both rigid block rheology and elastic block rheology for both block configurations and all boundaries were treated as free-slipping in the model.

In the single-block modeling results (ILHU) we found that the fit was generally good with a clockwise rotation of $40.6 \pm 2.3^{\circ} \mathrm{Myr}^{-1}$ and an Euler pole located southwest of the block (Fig. 7a). However, a misfit in the Hualien City area appears to be quite large. In the two-block model (RYUK + HUAL, Fig. 7b), the modeling revealed smaller reduced $\chi^{2}$ than the one-single-block model, particularly for stations in the HUAL block. In addition, the elastic block rheology fit better than that of the rigid block (Table 3). In Fig. 7b of the two-block model, both the RYUK and HUAL blocks show clockwise rotation at pole rotation rates of $42.4 \pm 3.0^{\circ}$ and $33.3 \pm 8.9^{\circ} \mathrm{Myr}^{-1}$, respectively. The RYUK block Euler pole position is located in the Central Range (similar to the single-block model) (Fig. 7b). The Euler pole for the HUAL block is located southwest of Hualien City as mentioned earlier in this section (compare Figs. 5a and 7b). We noticed that the small HUAL block shows a very important

Table 3. Summary of reduced chi-square values on block rotation models. The configuration of each block is shown in Fig. 6.

\begin{tabular}{ccccccc}
\hline Model description & No. of data & No. of free parameters & DOF $^{1}$ & reduced $\boldsymbol{\chi}^{2}$ & Total $\boldsymbol{\chi}^{\mathbf{2}}$ & Prob. ${ }^{2}(\%)$ \\
\hline HUAL & 48 & 6 & 42 & 1.183 & 49.67 & 19.43 \\
HUAL without internal strain & 48 & 3 & 45 & 4.333 & 194.99 & 0 \\
RYUK + HUAL & 72 & 12 & 60 & 1.642 & 98.53 & 0.127 \\
RYUK + HUAL without internal strain & 72 & 6 & 66 & 5.063 & 334.18 & 0 \\
ILHU & 72 & 6 & 66 & 2.458 & 162 & 0 \\
ILHU without internal strain & 72 & 3 & 69 & 10.316 & 711.84 & 0 \\
\hline
\end{tabular}

Note $:{ }^{1}$ DOF $=$ Degrees of Freedom.${ }^{2}$ Prob.$=$ Probability to fit.

Table 4. Euler vectors and internal principle strain rate of the blocks (relative to the Eurasian Plate).

\begin{tabular}{cccccccc}
\hline Block & Pole lon $(\mathbf{d e g})$ & Pole lat $(\mathbf{d e g})$ & Rotation rate $\left({ }^{\circ} \mathbf{M y r}^{-1}\right)$ & Azimuth $^{\mathbf{a}}$ & $\boldsymbol{\varepsilon}_{\mathbf{1}}\left(\mathbf{1 0}^{-\mathbf{6}} \mathbf{y r}^{-\mathbf{1}}\right)$ & $\boldsymbol{\varepsilon}_{\mathbf{2}}\left(\mathbf{1 0}^{-\mathbf{6}} \mathbf{y r}^{-\mathbf{1}}\right)$ & ${\text { Azimuth } \boldsymbol{\varepsilon}_{\mathbf{1}}}$ \\
\hline ILHU & 121.305 & 23.852 & $-40.6 \pm 2.3$ & 212.2 & $-0.517 \pm 0.026$ & $0.378 \pm 0.094$ & $-11.6 \pm 2.7$ \\
RYUK & 121.299 & 23.867 & $-42.4 \pm 3.0$ & 203.3 & $-0.439 \pm 0.049$ & $0.34 \pm 0.11$ & $-8 \pm 3.9$ \\
HUAL & 121.554 & 23.92 & $-33.3 \pm 8.9$ & 206.6 & $-1.59 \pm 0.15$ & $0.99 \pm 0.30$ & $-23.7 \pm 3.7$ \\
\hline
\end{tabular}

Note: ${ }^{a}$ Azimuth of pole error ellipse semi-major axis 

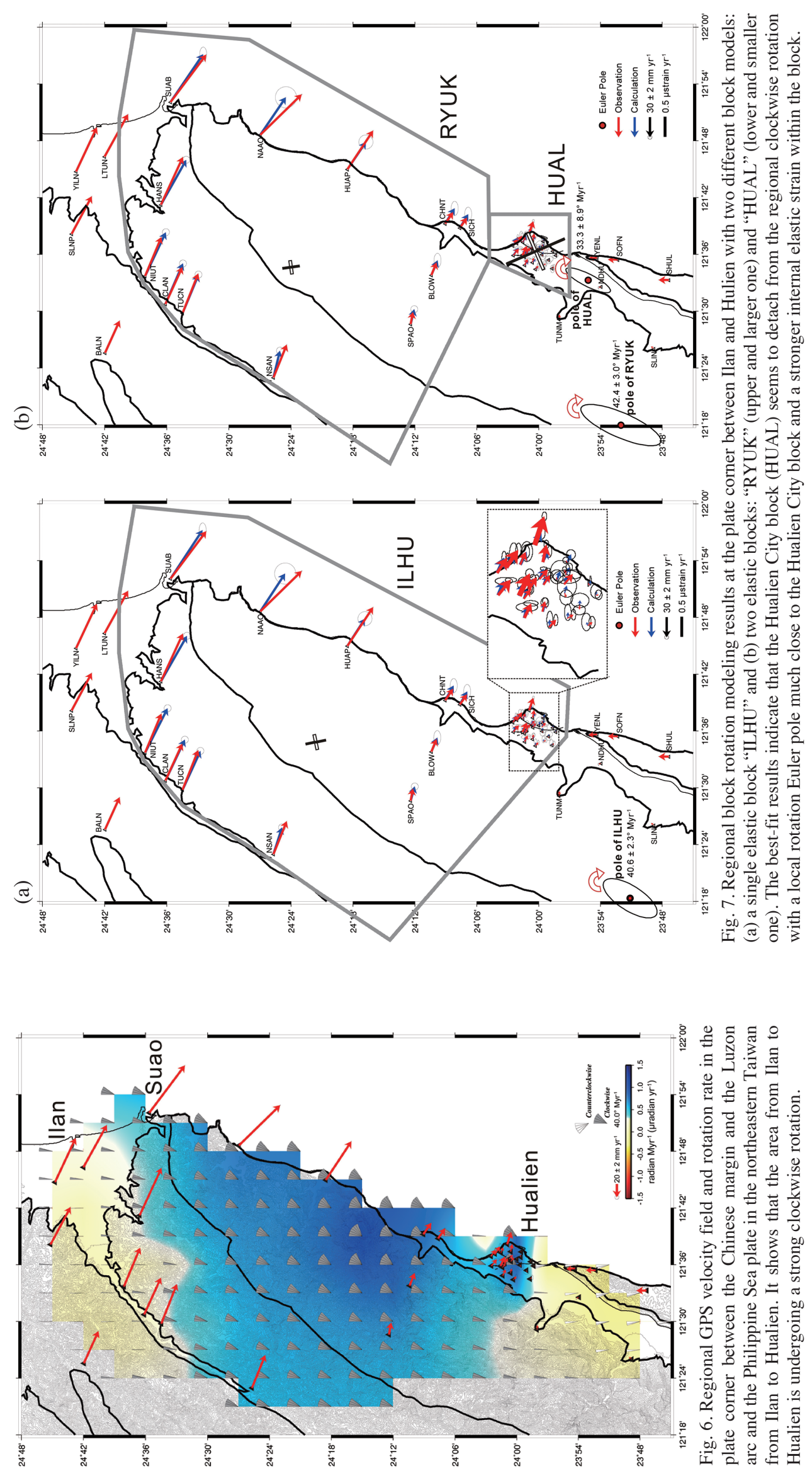
internal elastic strain greater than that in the larger RYUK block (Table 3). Based on the above analyses and results, we propose that the Hualien City area deserves to be considered an individual block (or micro-block), which seems to be detached from the whole area from Ilan to Hualien in the corner of the plate indentation.

Combining the results for the above strain analysis and block rotation modeling, the 2007 - 2009 surface deformation in the Hualien area was characterized by a strong clockwise rotation, coupled with a few possible minor strike-slip faults within the Milun Tableland. The Milun Tableland exhibited a distinct style of deformation different from the plain area. The plain area showed a clockwise rotation with mostly convergence-parallel NW-trending shortening with little shear strain. As a result, we interpreted that it behaves largely in a 'pure shear' style. By contrast, the Milun tableland revealed a rotation with a strong shear strain with $\mathrm{E}-\mathrm{W}$ extension in its northern part and NW shortening in the south: i.e., a transtension tectonic regime in the northern Milun tableland and a transpression regime in its southern part. We consider the Milun Tableland behaves as a 'simple shear' style. Furthermore, it appears that the Milun fault indeed marks a bound- ary in terms of deformation style (i.e., pure shear vs. simple shear) in the Hualien area. No significant strain concentration can be found along the surface trace of the Milun fault. In the following section we describe our near-fault kinematics analysis in an attempt to better delineate the Milun fault structural characterization.

\section{NEAR FAULT ANALYSIS ACROSS THE MILUN FAULT}

To better understand the active motion along the Milun fault and its kinematic characteristics we analyzed 3 velocity profiles perpendicular to the fault trace on which we projected velocities of the nearby GPS stations to the profiles with two components: along the fault strike and normal to the fault strike (Fig. 8). In this configuration, the increase in the along-strike component means left-lateral slip and an increase in the across-strike component suggests extensional deformation and vice versa.

First in Fig. 8a, the northernmost profile AA' indicates a small amount of sinistral slip at a rate of about $3 \pm 2 \mathrm{~mm} \mathrm{yr}^{-1}$ (red line) and an equal small amount of shortening of about
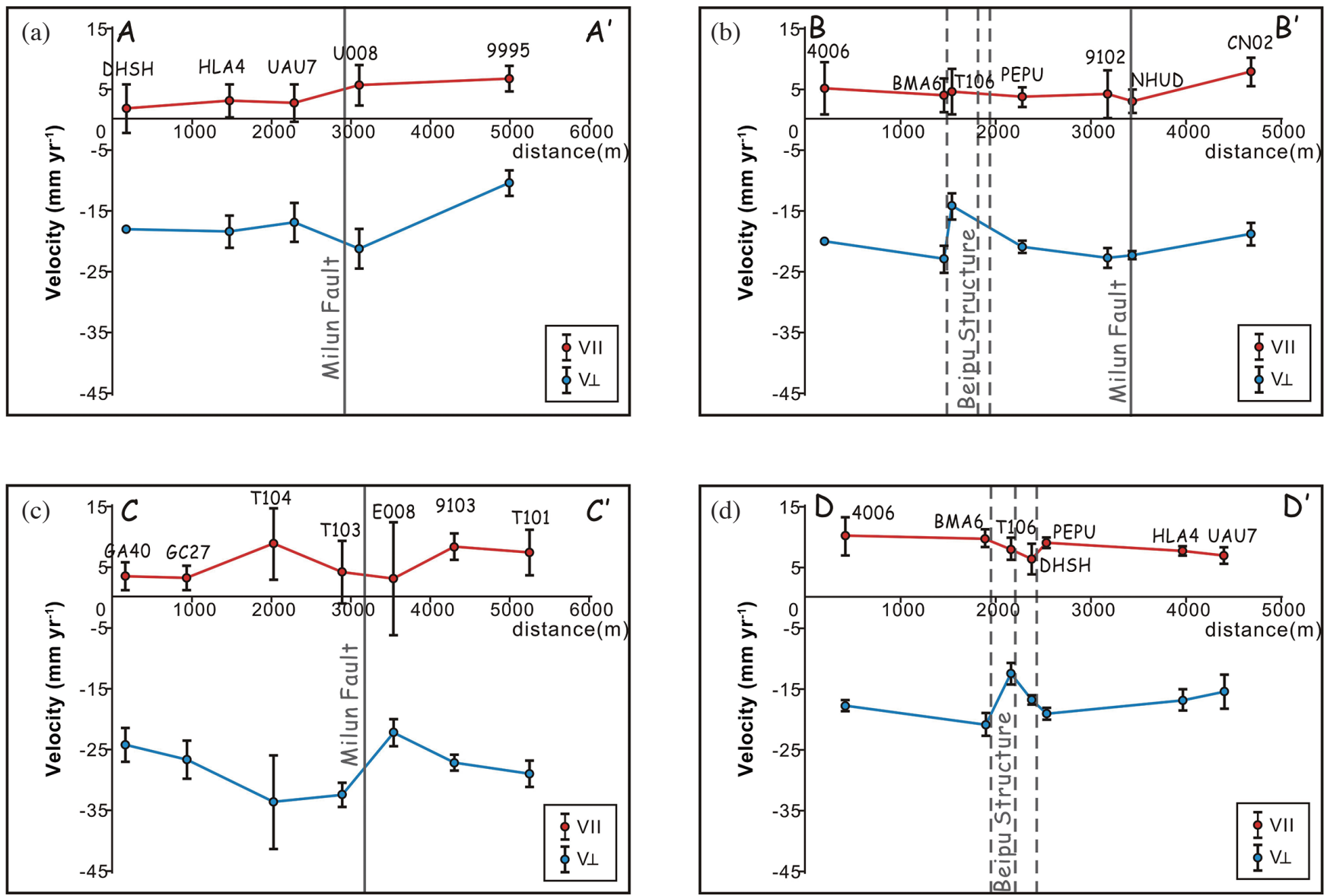

Fig. 8. GPS velocity profiles perpendicular to the active structures trend in the Hualien City area. The location of the profiles: see Fig. 3. Dark Gray lines represent the location of the faults. Red and blue circles represent velocities projected to the direction parallel to the fault strike and normal to the fault strike, respectively. See the text for detailed explanations. 
$2 \pm 2 \mathrm{~mm} \mathrm{yr}^{-1}$ (blue line) across the Milun fault. We tend to interpret that it indicates no significant change in velocity across the fault along the northern profile AA'. We also observed the Milun Tableland (hanging wall of the Milun fault) revealed a noticeable extension of $11 \pm 2 \mathrm{~mm} \mathrm{yr}^{-1}$ at a distance of $2 \mathrm{~km}$ between stations U008 and 9995 in the northern Milun tableland (blue line in Fig. 8a). Further south there is also no significant velocity change across the Milun fault on the middle BB' profile (Fig. 8b). By contrast we found a noticeable sinistral slip inside of the 2-km-wide Milun Tableland at a rate of $4-5 \mathrm{~mm} \mathrm{yr}^{-1}$ (red line). Note that a disturbance in velocity changes can also be observed across the Beipu structure, which we shall discuss later in the Discussion Section. In the CC' southern profile (Fig. 8c) an extension across the Milun fault at a rate of about $5.3 \pm 2 \mathrm{~mm} \mathrm{yr}^{-1}$ (blue line) and a small amount of shortening occurred in both the hanging and footwall. However, the lateral movement cannot be determined partly due to large uncertainties in the GPS results along this profile.

Based on the above analysis of these three profiles perpendicular to the Milun fault coupled with the aforementioned strain analyses, we concluded that the Milun fault had little surface movement across the surface trace with an unclear slip behavior variation in both the along-strike and across-strike components. By contrast, there was much substantial deformation in the hanging wall within the Milun Tableland with a large variation from north to south. Combining these results, we tend to interpret the Milun fault is probably presently locked, at least in the shallow crust level. On the other hand, the substantial deformation also indicates possible slip, such as visco-elastic ductile creep, at the deeper part of the Milun fault. It is still difficult to conduct more vigorous kinematic modeling due to the spatial limitations of the GPS network (i.e., narrow onland area of the hanging wall of the Milun fault).

\section{DISCUSSION}

\subsection{Vertical Movements and its Implications}

The vertical displacement accuracy from our 2-year GPS campaigned measurement is relatively poor, thus, the InSAR (Interferometry of Synthetic Aperture Radar) technique was applied to better constrain the Hualien area vertical deformation rate. We also paid particular attention on the deformation across the Milun fault. Hereafter we first present a recently published PSInSAR study from the ENVISAT satellite to illustrate the accumulated vertical deformation from $2004-2008$ (Yen et al. 2011). We then present our DInSAR study from the ERS satellite for the 1995 - 1998 and 1998 - 2000 deformations.

Yen et al. (2011) used Envisat radar images to derive PSI (Permanent Scatterer InSAR) time series and mean deformation during May 2004 to February 2008 (Fig. 9a).
From their result, the deformation across the Milun fault exhibits unremarkable velocity profiles (Fig. 9b). However a significant uplift occurred in the northern part of the Hualien City area (on both sides of the Milun fault) that was interpreted related to an earthquake swarm underneath the Hualien City area in 2005.

For comparison we also conducted a DInSAR (Differential Synthetic Aperture Radar Interferometry) using ERS radar images to estimate the vertical deformation during the 1995 - 2000 time span. With ERS radar small line-of-sight angle ( $23^{\circ}$ to vertical), the Slant Range Displacement (SRD) is sensitive to vertical ground motion. Although a radar wave can pass through clouds, mist and vapor, it could be attenuated after passing those media, thus the interferogram usually contains random noise due to turbulent atmospheric delays. To effectively decrease the random noise several independent interferograms were stacked to obtain the average value (Zebker et al. 1997).

Two stacking composite interferograms (I and II) were obtained from five independent interferograms, derived from eight ERS-2 SAR images (from Track 461, Frame 3123) in the Hualien area. The stacking interferogram I (Fig. 9c) duration covers a time span of two and a half years from December 1995 to August 1998. The stacking interferogram II (Fig. 9d) duration covers a two-year time span from March 1998 to August 2000, across the Mw = 7.6 Chi-Chi earthquake, which was the biggest earthquake that occurred in Taiwan during the last century with island wide surface deformation influence.

At a first glance, the two stacking interferograms (Figs. 9f and g) indeed exhibit different types of surface deformation. The northern part of the area, especially the Milun Tableland, revealed significant movement during the period across the Chi-Chi earthquake, which appears similar to the influence of the 2005 earthquake swarm observed in PSI analysis (Yen et al. 2011). During the 1995 - 1998 period the E - W AA' stacking interferogram I (Fig. 9c) profile shows there was no significant SRD rate difference across the Hualien City area, including the Milun fault (about $1 \mathrm{~mm} \mathrm{yr}^{-1}$ ), which is generally consistent with the ENVISAT PSI results of 2004 - 2008 (Fig. 9b). The SRD rate trend along the profile also suggests the Milun fault is probably locked in the near surface with gradual strain accumulation. That is, the displacement is smallest near the fault, but gradationally increases as distance to the fault increases. We argue that the load stress of regional tectonics on the Milun fault accumulates during the interseismic period. However, it would be released by large earthquakes.

Interestingly, the same SRD rate profile derived from the stacking inteferogram II in the period across the ChiChi earthquake shows a totally different trend from stacking inteferogram I. The stacking inteferogram II (Fig. 9g) profile shows that the SRD rate gradually and significantly increased from west to east with a significant but gradual 


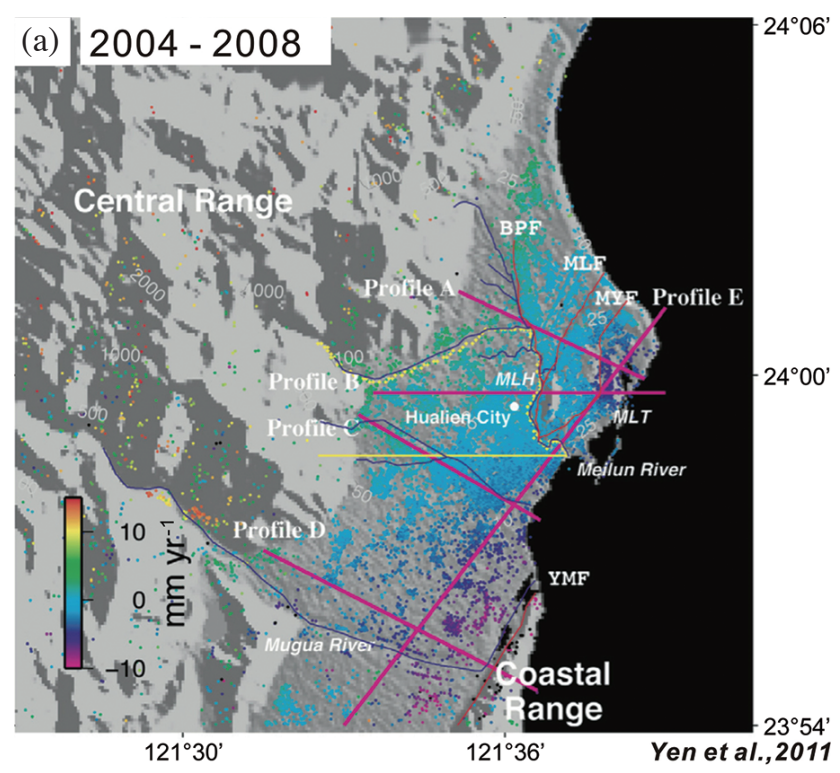

(b)

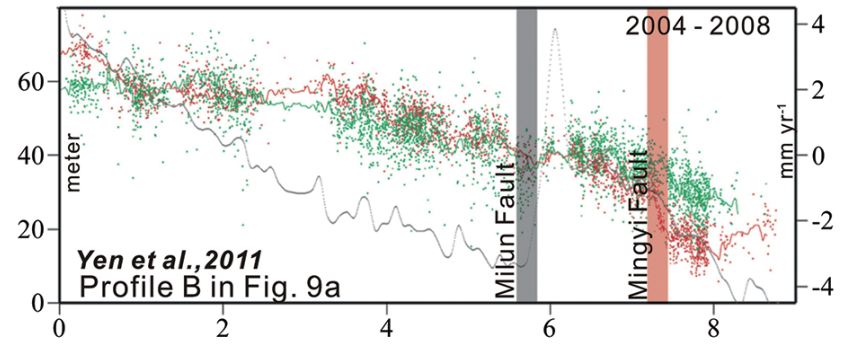

(c)

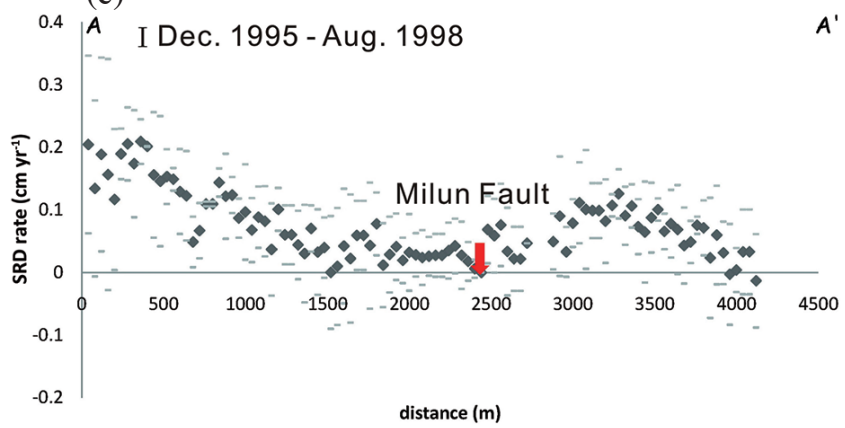

(d)

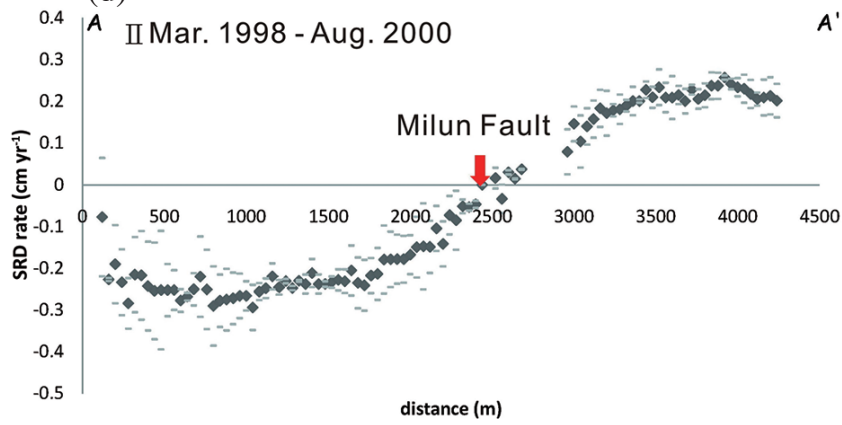

Fig. 9. (a) PSInSAR result of Yen et al. (2011) with two observation time spans of 1995 - 2001 and 2004 - 2008. (b) PSInSAR profile B in Fig. 9a. Red and green dots show individual PS points in the 1995 - 2001 and 2004 - 2008 time spans, respectively. Gray line represents topography along profile B. (c) SRD profile AA' of SAR interferogram I. (d) SRD profile AA' of interferogram II. (e) Information of observation time for each SAR image and interferogram. (f) Stacking interferogram I, time span from 1996 to 1998, before the Mw = 7.6 Chi-Chi earthquake. (g) Stacking interferogram II, time span from 1998 to 2000, across the Chi-Chi earthquake. (h) Cumulative number of earthquakes occurred in the Hualien City area from 1999 to 2001 

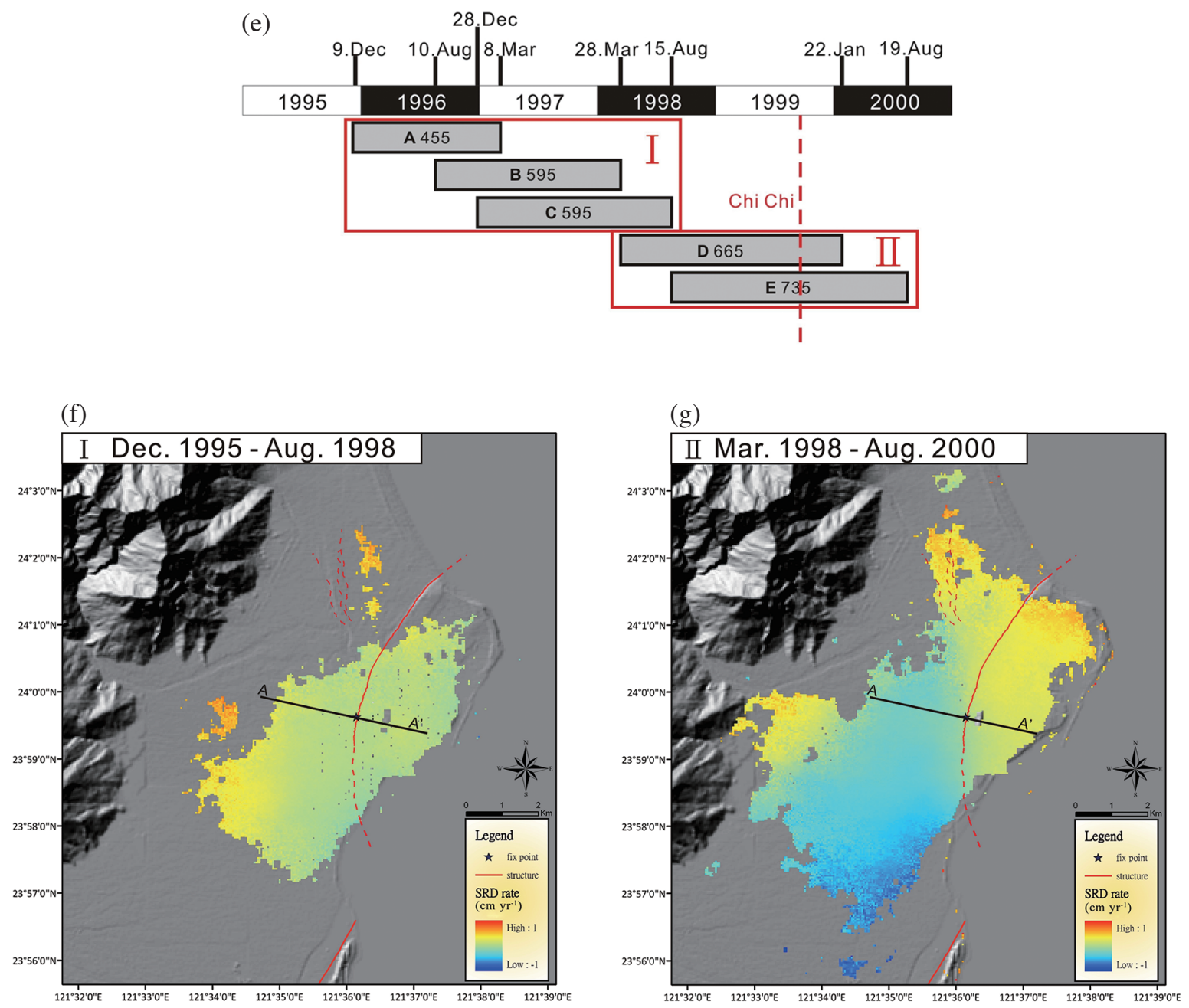

(h)

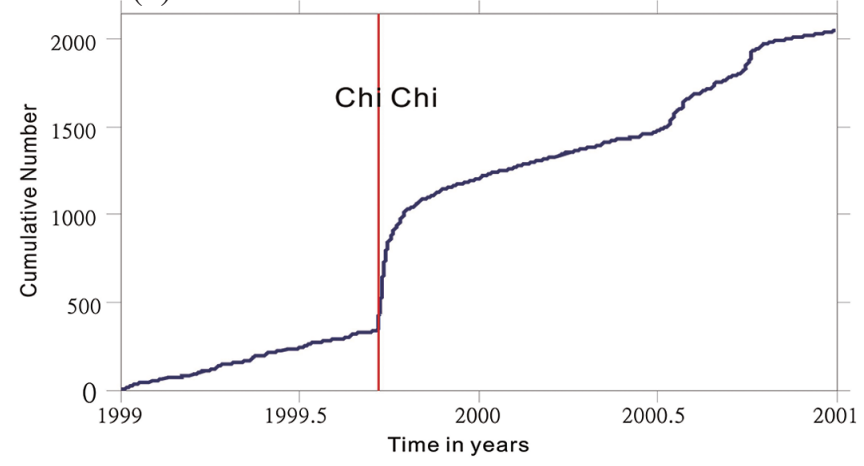

Fig. 9. (Continued)

increase of about $5 \mathrm{~mm} \mathrm{yr}^{-1}$ across the whole area in the AA' profile during 1998 - 2000. This implies that slip occurred on the deeper Milun fault segment and the fault was seemingly locked at the shallow part, assuming a half-space elastic dislocation on an east-dipping fault. As a result, we suspected that the Chi-Chi earthquake induced a local increase perturbation on the tectonic loading rate; thus trig- gering slip on the Milun fault at depth.

In order to clarify this suspicion the cumulative number of local earthquakes that occurred within $10 \mathrm{~km}$ of the Hualien area during the Chi-Chi earthquake in 1999 - 2001 was analyzed with the help of the CWB earthquake catalog (Central Weather Bureau) (Fig. 9h). The curve indicates a sudden increase in the number of earthquakes in the Hualien 
area after the Chi-Chi earthquake, especially in the first few months following the earthquake. Later the numbers returned to the average value. Comparing the SRD rate and cumulative number of earthquakes, we interpret that there was significant slip (accommodated by micro-earthquakes) on the deeper part of the Milun fault in 1998 - 2000, possibly triggered by the great Chi-Chi earthquake. After the Chi-Chi influence, we anticipate that the surface deformation would come back to the normal interseismic rate, with exceptions during occasional local earthquake swarms, for example the 2005 swarm mentioned above (Yen et al. 2011).

\subsection{Possible Other Active Faults}

In addition to the Milun fault some other potential active structures have been mentioned in this area. The first one is the NW-trending Beipu Structure, which is located in the northwest side of the Hualien Plain. It has been previously documented and highlighted by its abnormal topographic relief in a fluvial plain (Shih et al. 1983; Yang 1986). According to the geomorphic features we previously proposed that the Beipu Structure represents an active fault zone with a positive flower structure, presumably resulting from leftlateral strike slip (Chen et al. 2008). However, the fault activity remains uncertain. Our GPS results reveal a clear perturbation in both along-strike and across-strike directions while crossing the Beipu structure zone (Fig. 8d), which we presumably interpret as a result of pop-up deformation or a pressure ridge caused by the right-lateral strike slip faulting. As for the vertical deformation, unfortunately our InSAR analysis did not provide convincing results, although the stacking interferogram II shows a relative uplift in the Beipu area, compared to the plain area further south (Fig. 9g).

Based on the GPS strain analysis results the potential exists to have a few small local faults that show significant local movements in the Milun Tableland (Fig. 4). As mentioned above, we mapped some geomorphic lineaments in the northern and central Milun Tableland (i.e., the NE-trending Minyi fault and the NW-trending Dongmingyi fault, respectively) (Figs. 1c and 4d), which revealed different deformation patterns on each side of the lineaments. It indicates that those lineaments are probably active structures. It seems that the Milun Tableland is composed of several small blocks separated by these two possible active faults, in addition to the major boundary - the Milun fault. However, it still needs more investigation to identify and better characterize these two active structures.

\subsection{Complex Block Rotation, Tectonic Escape and the Milun Fault}

The most dominant deformation feature in the Hualien city area is the strong clockwise rotation, which also suggests tectonic escape of the northern end of the Longitudinal Valley, indented by the northern tip of the Coastal Range.
The Coastal Range not only compresses the Longitudinal Valley and the Central Range in a northwestward direction, but previous studies also showed that the Coastal Range starts to go down in the north (Liu et al. 1997; Lallemand et al. 1999), probably pulled by the subducting Philippine Sea plate (Wu et al. 2009). As a result, the Coastal Range continuously pushes the northern end of the Longitudinal Valley, including the Milun Tableland and the plain area and causes these areas to move upward, as shown in longterm uplifted late Quaternary marine terraces (Yamaguchi and Ota 2004) and short-term DInSAR analyses, but also eastward, as shown by our GPS vectors. The indenting area (or point) seems to be located between the northern Coastal Range and the Milun Tableland in the southern Hualien area, as suggested by the calculated Euler pole of the rotating Hualien block (Fig. 5).

On the other hand the clockwise rotation of the Hualien block with a rather rapid rate of $33.3 \pm 8.9^{\circ} \mathrm{Myr}^{-1}$ is far from a rigid block rotation. First the rotating Hualien block fits better with significant internal strain within the block. Second, the Milun fault acts as a boundary between the plain area characterized by a pure shear style of deformation to the west and the tableland area characterized by a simple shear style of deformation to the east. As a result, the Milun fault certainly plays an important role in complicating the strongly rotating Hualien block, which is pushed by the indenting arc of the Coastal Range, although the fault seems to be mostly locked in the interseismic period.

This mechanical rotation and escape behavior at the plate corner seems similar to the large-scale collision-extrusion tectonics which Tapponnier et al. (1982) first proposed to describe the tectonics of southeastern Asia in 1982. In fact, the crustal movement behavior in northeastern Taiwan, from Ilan to the Hualien area, has been interpreted as the result of tectonic extrusion plus possible additional nearby back-arc opening effects ( $\mathrm{Lu}$ et al. 1995; Hu et al. 2002; Rau et al. 2008; Angelier et al. 2009; Ching et al. 2011). The southernmost part of the extruded block in those studies is considered located near the village of Hoping, which is about $25-30 \mathrm{~km}$ north of Hualien City. However, our results show that the northernmost part of the Longitudinal Valley area (i.e., the Hualien city area) seems likely to belong to the southernmost part of this extruded block that shows similar behavior but exhibits a local rotation or extrusion (or escape) with a rotating pole much closer to the northern tip of the Coastal Range. We tend to interpret it as the near field and shallow crust effects at the plate corner (Fig. 10a).

Considering that the Milun fault probably developed in this rotation and escape tectonic framework, it would have to accommodate eastward and upward movement in the northern Hualien block. Combining the facts that the horizontal strike-slip displacement was a factor of 1.5 larger than the vertical dip-slip component in the $1951 \mathrm{M}_{\mathrm{L}}=7.3$ earthquake coseismic deformation, we tend to interpret that the Milun fault 

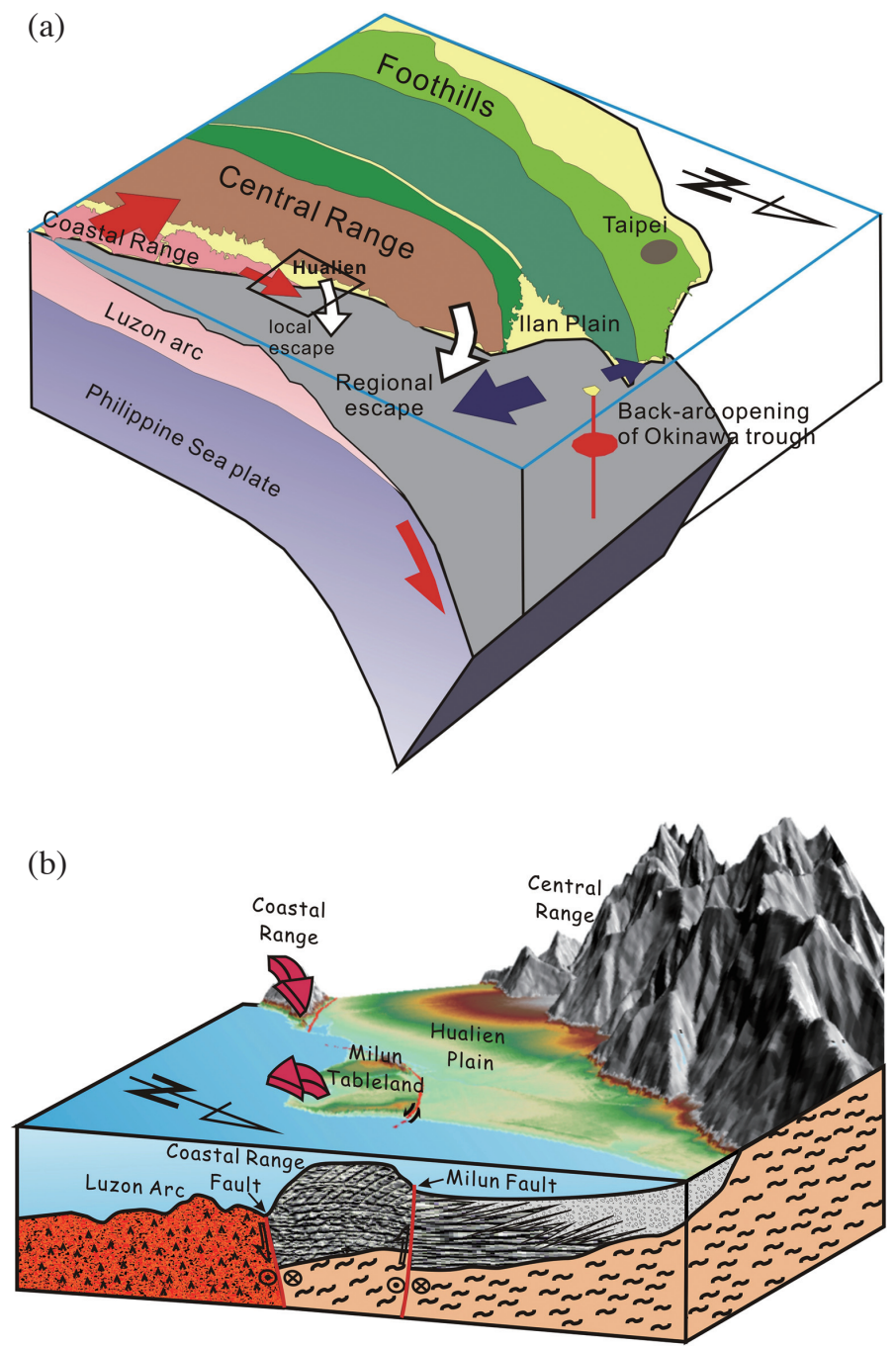

Fig. 10. (a) Schematic geological block diagram showing that the northeastern Taiwan (from Ilan to Hualien) is escaping toward the east. The northernmost of Longitudinal Valley area (the Hualien City area) appears to be the southernmost part of this extruded block, however, with its own rotating Euler pole and more significant internal elastic strain. (b) Schematic geological block diagram showing our interpretation for the relationship between the Longitudinal Valley fault (Coastal Range fault) and the Milun fault under the Milun tableland.

dip angle would be rather steep. In this case the Milun fault does not necessarily connect to the LVF at depth (Fig. 10b). This is in contradiction with previous suggestions that the Milun fault belongs to the LVF system and represents the frontal thrust of LVF (Hsu 1962). As the northern Coastal Range moves mostly northward and especially downward, it is mechanically difficult to propagate westward and create a new branch of thrust on the footwall side, such as the Milun fault. At this stage, based on our GPS results we interpret the Milun fault likely as a high-angle sinistral fault that might not belong to the LVF system. We therefore suspect that the Milun Tableland overlies the metamorphic terrain of the Central Range (Fig. 10b). However, further investigations still need to elucidate the subsurface structure of the Milun fault, such as geophysical imaging, more elaborated numerical modeling and so on. From a regional point of view the LVF is the major geological boundary fault between the
Longitudinal Valley and the Coastal Range, but the Milun fault is considered a relatively new active fault in the northernmost Longitudinal Valley and is induced by collisionescape tectonics and the process is still ongoing.

\section{CONCLUSIONS}

This study installed a dense campaigned GPS network of 25 stations and conducted repeated measurements six times from 2007 - 2009 in the northernmost Longitudinal Valley (the Hualien area) in Eastern Taiwan. Based on the GPS results the related strain rates, profile kinematic analyses and elastic block rotation modeling obtained the following conclusions.

(1) Most of the GPS stations exhibited a linear horizontal velocity trend during 2007 - 2009. As a result, we obtained a presumable inter-seismic secular GPS horizontal velocity 
field in the Hualien City area. The velocity vectors in the ITRF2000 reference frame show this area is escaping eastward with a rapid clockwise block rotation at a rate of about $33^{\circ} \mathrm{Myr}^{-1}$, which we interpreted as resulting from an indentation of the NNW moving Coastal Range.

(2) The deformation in the Hualien City area is, however, far from a rigid-block rotation. Elastic block rotation modeling indicated that the Hualien area better fit an elastic model with significant internal strain than a rigid block model. On the western side of the Milun fault, i.e., the causative fault of the $1951 \mathrm{M}_{\mathrm{L}}=7.3$ earthquake, the internal surface deformation of the alluvial plain is characterized by a pure shear style deformation with a dominant NNW-directed shortening and ENE-directed extension. On the eastern side of the fault in the Milun Tableland, a topographic high of 2-km wide and 8-km long, the internal surface deformation exhibits a simple shear style, which is characterized by a transtension strain with $\mathrm{E}-\mathrm{W}$ extension and $\mathrm{N}-\mathrm{S}$ compression in the northern tableland and a transpression strain with ENE extension and NNW compression in the southern part. These two distinct strain styles are separated by a possible active fault, the Dongmingyi Fault, trending NW in the middle of the Milun Tableland.

(3) In a large regional scale the Hualien area would represent the southernmost area of the tectonic escape zone from Ilan to Hualien of about $60 \mathrm{~km}$ long and a few tens of $\mathrm{km}$ wide at the plate corner of Eurasian continental margin, which are indented by the Luzon arc of the Philippine Sea plate. Our GPS data and elastic block rotation modeling illustrated that the Hualien area, about $10 \mathrm{~km}$ long and wide, acts as a micro-block detached from the Ilan-Hualien block with its own rotating Euler pole much closer to the block near the tip of the northern Coastal Range.

(4) The Milun fault showed little surface movement during 2007 - 2009. Our GPS measurements indicate that the shallow portion of the Milun fault is probably undergoing a locked stage now. On the other hand, the InSAR results revealed a significant perturbation of possible slip occurring at depth along the Milun fault during the 1999 $\mathrm{Mw}=7.6$ Chi-Chi earthquake and the 2005 local earthquake swarm, suggesting far-field large earthquakes or local moderate earthquakes might affect the interseismic slip on the deeper part of the Milun fault.

(5) Our results also suggest a few other possible active faults in the study area, including the Beipu fault in the Hualien Plain, Mingyi fault and the Dongmingyi fault in the Milun Tableland.

Acknowledgments We are grateful for many constructive comments and suggestions of the two anonymous Reviewers, which substantially improved this manuscript. The work was conducted mainly during the Master study of Chia-Yu Chen at National Taiwan University and Academia Sinica.
This research was also supported by the National Science Council of Taiwan (grants NSC101-2116-M-001-005 and NSC102-2116-M-001-016). We sincerely thank Shu-Chen Chiu, Ting-Chieh Lin and several students, who supplied generous assistance during our field GPS campaigned surveys. Special thanks are also given to Horng-Yue Chen for his advice and help with GPS data positioning determination processing. This is a contribution of Institute of Earth Sciences, Academia Sinica, IESAS1853.

\section{REFERENCES}

Angelier, J., F. Bergerat, H. T. Chu, and T. Q. Lee, 1990: Tectonic analysis and the evolution of a curved collision belt: The Hsüehshan Range, Northern Taiwan. Tectonophysics, 183, 77-96, doi: 10.1016/0040-1951(90)90189-F. [Link]

Angelier, J., H. T. Chu, and J. C. Lee, 1997: Shear concentration in a collision zone: Kinematics of the Chihshang Fault as revealed by outcrop-scale quantification of active faulting, Longitudinal Valley, eastern Taiwan. Tectonophysics, 274, 117-143, doi: 10.1016/ S0040-1951(96)00301-0. [Link]

Angelier, J., T. Y. Chang, J. C. Hu, C. P. Chang, L. Siame, J. C. Lee, B. Deffontaines, H. T. Chu, and C. Y. Lu, 2009: Does extrusion occur at both tips of the Taiwan collision belt? Insights from active deformation studies in the Ilan Plain and Pingtung Plain regions. Tectonophysics, 466, 356-376, doi: 10.1016/j.tecto.2007.11.015. [Link]

Barrier, E. and J. Angelier, 1986: Active collision in eastern Taiwan: The Coastal Range. Tectonophysics, 125, 3972, doi: 10.1016/0040-1951(86)90006-5. [Link]

Biq, C. C., 1965: The east Taiwan Rift. Pet. Geol. Taiwan, 4, 93-106.

Burbank, D. W. and R. S. Anderson, 2001: Tectonic Geomorphology, Blackwell Science, Wiley, 274 pp.

Chen, C., J. Lee, R. Chen, and Y. Chen, 2008: Present-day crustal deformation and neotectonics in northern Hualien, Taiwan. American Geophysical Union, Fall Meeting 2008, abstract \#T53D-1975.

Chen, C. F., J. B. H. Shyu, and Y. M. Wu, 2012: Seismotectonic characteristics of the northernmost part of the Longitudinal Valley suture, eastern Taiwan. EGU General Assembly 2012, held 22-27 April, 2012 in Vienna, Austria., p.5459.

Chen, H. and R. Rau, 2002: Earthquake locations and style of faulting in an active arc-continent plate boundary: The Chihshang fault of eastern Taiwan. AGU Fall Meeting.

Chen, W. and Y. Wang, 1986: Coastal Range geology in eastern Taiwan, Cent. Geol. Surv., Taipei, 101 pp.

Ching, K. E., R. J. Rau, K. M. Johnson, J. C. Lee, and J. C. $\mathrm{Hu}, 2011$ : Present-day kinematics of active mountain 
building in Taiwan from GPS observations during 1995-2005. J. Geophys. Res., 116, B09405, doi: 10.1029/2010JB008058. [Link]

Crespi, J. M., Y. C. Chan, and M. S. Swaim, 1996: Synorogenic extension and exhumation of the Taiwan hinterland. Geology, 24, 247-250, doi: 10.1130/0091-7613(1 996)024<0247:Seaeot>2.3.Co;2. [Link]

Dach, R., U. Hugentobler, P. Fridez, and M. Meindl, 2007: Bernese GPS Software Version 5.0, Astronomical Institute, University of Bern, Switzerland.

Ho, C. S., 1982: Tectonic Evolution of Taiwan: Explanatory Text of the Tectonic Map of Taiwan, Ministry of Economic Affairs, Republic of China, Taipei, $236 \mathrm{pp}$.

Ho, C. S., 1986: A synthesis of the geologic evolution of Taiwan. Tectonophysics, 125, 1-16, doi: 10.1016/00401951(86)90004-1. [Link]

Hsu, S. K., 2001: Subduction/collision complexities in the Taiwan-Ryukyu junction area: Tectonics of the northwestern corner of the Philippine Sea plate. Terr. Atmos. Ocean. Sci., 12, 209-230.

Hsu, T. L., 1955: The earthquakes of Taiwan. Quart. J. Bank Taiwan, 7, 39-63. (in Chinese)

Hsu, T. L., 1962: Recent faulting in the Longitudinal Valley of eastern Taiwan. Memoir Geol. Soc. China, 1, 95-102.

Hu, J. C., S. B. Yu, H. T. Chu, and J. Angelier, 2002: Transition tectonics of northern Taiwan induced by convergence and trench retreat. Geol. Soc. Am., 358, 147-160, doi: 10.1130/0-8137-2358-2.147. [Link]

Jahn, B. M., F. Martineau, J. J. Peucat, and J. Cornichet, 1986: Geochronology of the Tananao Schist complex, Taiwan, and its regional tectonic significance. Tectonophysics, 125, 103-124, doi: 10.1016/0040-1951(86)90009-0. [Link]

Kao, H. and P. R. Jian, 2001: Seismogenic patterns in the Taiwan region: Insights from source parameter inversion of BATS data. Tectonophysics, 333, 179-198, doi: 10.1016/S0040-1951(00)00274-2. [Link]

Kao, H., S. S. J. Shen, and K. F. Ma, 1998: Transition from oblique subduction to collision: Earthquakes in the southernmost Ryukyu arc-Taiwan region. J. Geophys. Res., 103, 7211-7229, doi: 10.1029/97jb03510. [Link]

Kuo, L. C., 2001: High precision GPS surveying for crustal deformation study. Ph.D. Thesis, National Chiao-Tung University, Taiwan. (in Chinese)

Kuochen, H., Y. M. Wu, C. H. Chang, J. C. Hu, and W. S. Chen, 2004: Relocation of eastern Taiwan earthquakes and tectonic implications. Terr. Atmos. Ocean.Sci., 15, 647-666.

Lallemand, S., C. S. Liu, S. Dominguez, P. Schnürle, J. Malavieille, J. Angelier, J. Y. Collot, B. Deffontaines, M. Fournier, S. K. Hsu, J. P. Le Formal, S. Y. Liu, C. Y. Lu, J. C. Sibuet, N. Thareau, and F. Wang, 1999: Trench-parallel stretching and folding of forearc basins and lateral migration of the accretionary wedge in the southern Ryukyus: A case of strain partition caused by oblique convergence. Tectonics, 18, 231-247, doi: 10.1029/1998tc900011. [Link]

Lallemand, S., Y. Font, H. Bijwaard, and H. Kao, 2001: New insights on 3-D plates interaction near Taiwan from tomography and tectonic implications. Tectonophysics, 335, 229-253, doi: 10.1016/S0040-1951(01)00071-3. [Link]

Lee, J. C. and J. Angelier, 1993: Location of active deformation and geodetic data analyses: an example of the Longitudinal Valley Fault, Taiwan. Bull. Soc. Geol. France, 164, 533-570.

Lee, J. C., J. Angelier, H. T. Chu, J. C. Hu, F. S. Jeng, and R. J. Rau, 2003: Active fault creep variations at Chihshang, Taiwan, revealed by creep meter monitoring, 1998-2001. J. Geophys. Res., 108, doi: 10.1029/2003JB002394. [Link]

Lee, J. C., H. T. Chu, J. Angelier, J. C. Hu, H. Y. Chen, and S. B. Yu, 2006: Quantitative analysis of surface coseismic faulting and postseismic creep accompanying the 2003, $M w=6.5$, Chengkung earthquake in eastern Taiwan. J. Geophys. Res., 111, B02405, doi: 10.1029/2005JB003612. [Link]

Lin, C. H., 2000: Thermal modeling of continental subduction and exhumation constrained by heat flow and seismicity in Taiwan. Tectonophysics, 324, 189-201, doi: 10.1016/S0040-1951(00)00117-7. [Link]

Lin, C. H., Y. H. Yeh, H. Y. Yen, K. C. Chen, B. S. Huang, S. W. Roecker, and J. M. Chiu, 1998: Three-dimensional elastic wave velocity structure of the Hualien region of Taiwan: Evidence of active crustal exhumation. Tectonics, 17, 89-103, doi: 10.1029/97tc02510. [Link]

Lin, M. S. and C. L. Hsiao, 1998: The strike-slip fault system in the Milun Tableland. Res. of Eastern Taiwan, 3, 13-30. (in Chinese)

Liu, C. S., P. Schnürle, S. Lallemand, and D. L. Reed, 1997: TAICRUST and deep seismic imaging of western end of the Ryukyu arc-trench system. JAMSTEC J. Deep Sea Res., 39-45.

Lu, C. and K. Hsu, 1992: Tectonic evolution of the Taiwan mountain belt. Pet. Geol. Taiwan, 27, 21-46.

Lu, C. Y., J. Angelier, H. T. Chu, and J. C. Lee, 1995: Contractional, transcurrent, rotational and extensional tectonics: Examples from northern Taiwan. Tectonophysics, 246, 129-146, doi: 10.1016/0040-1951(94)00252-5. [Link]

Malavieille, J., S. E. Lallemand, S. Dominguez, A. Deschamps, C. Y. Lu, C. S. Liu, P. Schnürle, J. Angelier, J. Y. Collot, B. Deffontaines, M. Fournier, S. K. Hsu, J. P. Le Formal, S. Y. Liu, J. C. Sibuet, N. Thareau, and F. Wang, 2002: Arc-continent collision in Taiwan: New marine observations and tectonic evolution. Geol. 
Soc. Am., 358, 187-211, doi: 10.1130/0-8137-23582.187. [Link]

McCaffrey, R., 2002: Crustal block rotations and plate coupling. In: Stein, S. and J. Freymueller (Eds.), Plate Boundary Zones, AGU Geodynamics Series 30, 101122.

Rau, R. J., K. E. Ching, J. C. Hu, and J. C. Lee, 2008: Crustal deformation and block kinematics in transition from collision to subduction: Global positioning system measurements in northern Taiwan, 1995-2005. J. Geophys. Res., 113, B09404, doi: 10.1029/2007JB005414. [Link]

Shen, Z. K., D. D. Jackson, and B. X. Ge, 1996: Crustal deformation across and beyond the Los Angeles basin from geodetic measurements. J. Geophys. Res., 101, 27957-27980, doi: 10.1029/96jb02544. [Link]

Shih, T. T., J. Chang, C. Hwang, C. Shih, and G. Yang, 1983: A geomorphological study of active fault in northern and eastern Taiwan. Geogr. Stud., 9, 20-72. (in Chinese)

Shyu, J. B. H., K. Sieh, Y. G. Chen, and C. S. Liu, 2005: Neotectonic architecture of Taiwan and its implications for future large earthquakes. J. Geophys. Res., 110, B08402, doi: 10.1029/2004jb003251. [Link]

Suppe, J., 1984: Kinematics of arc-continent collision, flipping of subduction, and back-arc spreading near Taiwan. Memoir Geol. Soc. China., 6, 21-33.

Tapponnier, P., G. Peltzer, A. Y. Le Dain, R. Armijo, and P. Cobbold, 1982: Propagating extrusion tectonics in Asia: New insights from simple experiments with plasticine. Geology, 10, 611-616, doi: 10.1130/0091-7613( 1982) 10<611:PETIAN>2.0.CO;2. [Link]

Teng, L. S., 1990: Geotectonic evolution of late Cenozoic arc-continent collision in Taiwan. Tectonophysics, 183, 57-76, doi: 10.1016/0040-1951(90)90188-E. [Link]

Teng, L. S. and Y. Wang, 1981: Island arc system of the Coastal Range, eastern Taiwan. Proc. Geol. Soc. Chi$n a$, 24, 99-112.

Ward, S. N., 1998: On the consistency of earthquake moment rates, geological fault data, and space geodetic strain: The United States. Geophys. J. Int., 134, 172186, doi: 10.1046/J.1365-246x.1998.00556.X. [Link]

Wu, Y. M., Y. G. Chen, T. C. Shin, H. Kuochen, C. S. Hou, J. C. Hu, C. H. Chang, C. F. Wu, and T. L. Teng, 2006: Coseismic versus interseismic ground deformations, fault rupture inversion and segmentation revealed by $2003 M w 6.8$ Chengkung earthquake in eastern Taiwan. Geophys. Res. Lett., 33, L02312, doi: 10.1029/2005g1024711. [Link]

Wu, Y. M., C. H. Chang, L. Zhao, T. L. Teng, and M. Nakamura, 2008: A comprehensive relocation of earthquakes in Taiwan from 1991 to 2005. Bull. Seismol. Soc. Am., 98, 1471-1481, doi: 10.1785/0120070166. [Link]
Wu, Y. M., J. B. H. Shyu, C. H. Chang, L. Zhao, M. Nakamura, and S. K. Hsu, 2009: Improved seismic tomography offshore northeastern Taiwan: Implications for subduction and collision processes between Taiwan and the southernmost Ryukyu. Geophys. J. Int., 178, 1042-1054, doi: 10.1111/J.1365-246x.2009.04180.X. [Link]

Yamaguchi, M. and Y.Ota, 2004: Tectonic interpretations of Holocene marine terraces, east coast of Coastal Range, Taiwan. Quat. Int., 115-116, 71-81, doi: 10.1016/ S1040-6182(03)00097-1. [Link]

Yang, G. S., 1986: A geomorphological study of active faults in Taiwan-especially on the relation between active faults and geomorphic surfaces. Ph. D. Thesis, Chinese Culture University, Taipei, Taiwan, 178 pp. (in Chinese)

Yen, J. Y., C. H.Lu, C. P. Chang, A. J. Hooper, Y. H. Chang, W. T. Liang, T. Y. Chang, M. S. Lin, and K. S. Chen, 2011: Investigating active deformation in the northern Longitudinal Valley and City of Hualien in eastern Taiwan using persistent scatterer and small-baseline SAR interferometry. Terr. Atmos. Ocean. Sci., 22, 291-304, doi: 10.3319/Tao.2010.10.25.01(Tt). [Link]

Yu, M.S., 1994: Wrench-fault characteristics of the Taitung Longitudinal Valley Fault zone. Ti-Chih, 14, 121-147. (in Chinese)

Yu, S. B. and C. W. Lee, 1986: Geodetic measurement of horizontal crustal deformation in eastern Taiwan. Tectonophysics, 125, 73-85, doi: 10.1016/0040-1951(86)90007-7. [Link]

Yu, S. B. and L. C. Kuo, 2001: Present-day crustal motion along the Longitudinal Valley Fault, eastern Taiwan. Tectonophysics, 333, 199-217, doi: 10.1016/S00401951(00)00275-4. [Link]

Yu, S. B., D. D. Jackson, G. K. Yu, and C. C. Liu, 1990: Dislocation model for crustal deformation in the Longitudinal Valley area, eastern Taiwan. Tectonophysics, 183, 97-109, doi: 10.1016/0040-1951(90)90190-J. [Link]

Yu, S. B., H. Y. Chen, and L. C. Kuo, 1997: Velocity field of GPS stations in the Taiwan area. Tectonophysics, 274, 41-59, doi: 10.1016/S0040-1951(96)00297-1. [Link]

Yui, T. F., T. W. Wu, and B. Jahn, 1990: Geochemistry and plate-tectonic significance of the metabasites from the Tananao Schist Complex of Taiwan. J. Southeast Asian Earth Sci., 4, 357-368, doi: 10.1016/0743-9547(90)90006-Y. [Link]

Zebker, H. A., P. A. Rosen, and S. Hensley, 1997: Atmospheric effects in interferometric synthetic aperture radar surface deformation and topographic maps. J. Geophys. Res., 102, 7547-7563, doi: 10.1029/96jb03804. [Link] 